\title{
Managing Risk Taking with Interest Rate Policy and Macroprudential Regulations
}

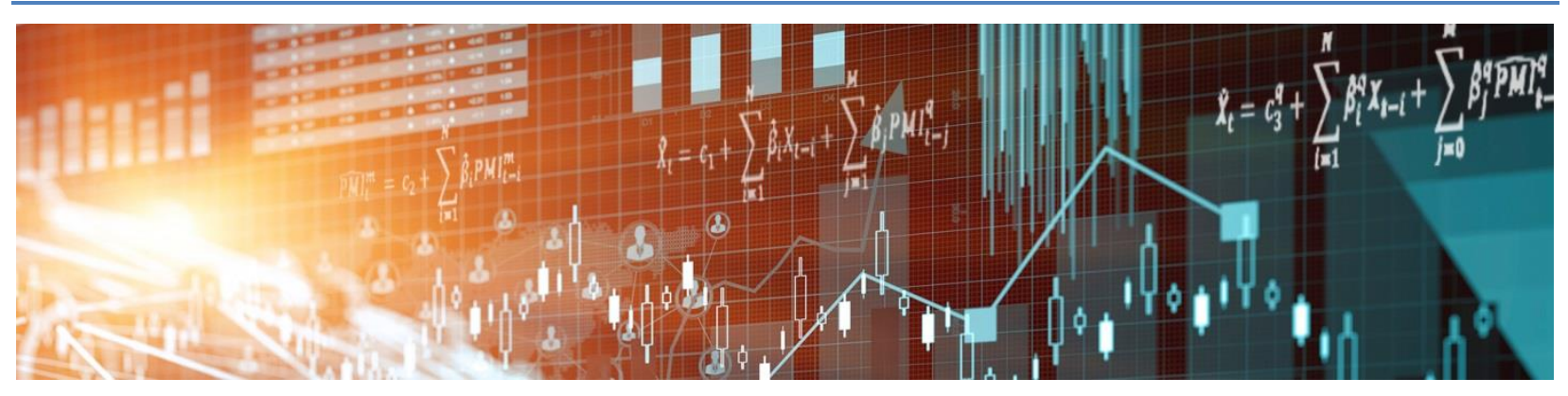

by Simona E. Cociuba, Malik Shukayev and Alexander Ueberfeldt 
Bank of Canada Staff Working Paper 2016-47

November 2016

\section{Managing Risk Taking with Interest Rate Policy and Macroprudential Regulations}

By

Simona E. Cociuba, ${ }^{1}$ Malik Shukayev, ${ }^{2}$ and Alexander Ueberfeldt ${ }^{3}$

${ }^{1}$ Corresponding author: Department of Economics, University of Western Ontario, scociuba@uwo.ca

2University of Alberta, shukayev@ualberta.ca

${ }^{3}$ Canadian Economic Analysis Department

Bank of Canada

Ottawa, Ontario, Canada K1A 0G9

aueberfeldt@bankofcanada.ca 


\section{Acknowledgements}

We thank Klaus Adam, V.V. Chari, Skander Van den Heuvel, Brent Glover, Jim MacGee, Ali Ozdagli, Ananth Ramanarayanan, Carlos Zarazaga and Ariel Zetlin-Jones for useful comments and suggestions. Cociuba is grateful for financial support from the Academic Development Fund of the University of Western Ontario and from the Social Sciences and Humanities Research Council (SSHRC).

The views expressed herein are those of the authors and not necessarily those of the Bank of Canada. 


\begin{abstract}
We develop a model in which a financial intermediary's investment in risky assets—risk taking - is excessive due to limited liability and deposit insurance and characterize the policy tools that implement efficient risk taking. In the calibrated model, coordinating interest rate policy with state-contingent macroprudential regulations, either capital or leverage regulation, and a tax on profits achieves efficiency. Interest rate policy mitigates excessive risk taking by altering both the return and the supply of collateralizable safe assets. In contrast to commonly used capital regulation, leverage regulation has stronger effects on risk taking and calls for higher interest rates.
\end{abstract}

Bank topic(s): Financial system regulation and policies, Monetary policy framework JEL code(s): E44, E52, G11, G18

\title{
Résumé
}

Nous construisons un modèle dans lequel les montants des placements en actifs risqués effectués par un intermédiaire financier - la prise de risques - sont excessifs en raison d'une limitation de la responsabilité et de l'assurance-dépôts. Nous définissons également les instruments de politique qui permettent une prise de risques efficiente. Dans ce modèle étalonné, coordonner la politique de taux d'intérêt avec une réglementation macroprudentielle conditionnelle à l'état de l'économie - qu'il s'agisse de la réglementation des fonds propres, de celle du levier financier ou de l'impôt sur les bénéfices - permet d'atteindre l'efficience. La politique de taux d'intérêt atténue la prise de risques excessifs en influant sur l'offre d'actifs sûrs pouvant servir de garanties, ainsi que sur leur rendement. Contrairement à la réglementation des fonds propres couramment utilisée, la réglementation du levier financier a des effets plus importants sur la prise de risques et nécessite le relèvement des taux d'intérêt.

Sujet(s) : Réglementation et politiques relatives au système financier, Cadre de la politique monétaire

Code(s) JEL : E44, E52, G11, G18 


\section{Non-Technical Summary}

The recent financial crisis brought to the forefront discussions regarding the optimal design of monetary policy and financial regulations. Policymakers and macroeconomists alike have commented on the extent to which monetary policy should respond to a buildup of risk in the financial sector, and whether monetary policy should be coordinated with regulation to ensure economic and financial stability. Recent studies have concluded that accommodative monetary policy leads banks to invest more in risky assets, and that strict financial regulations slow down economic growth. In this paper, we examine the interaction between monetary policy and financial regulations in achieving socially optimal risk taking by the financial sector.

To this end, we develop a quantitative model in which financial intermediaries' risky investments (i.e., risk taking) over the business cycle may exceed the social optimum, due to limited liability and deposit insurance. However, intermediaries' risk taking is influenced by monetary policy and by macroprudential policies, namely, financial regulations on capital or leverage, and profit taxes. We focus on time-varying macroprudential policies, which alleviate the moral hazard of intermediaries during expansions while being more lenient during recessions. Our main contribution is to show that the optimal policy tools need to be coordinated to deter excessive risk taking and to implement the social optimum. Specifically, monetary policy rates are higher in the presence of leverage regulation than with capital regulation. Moreover, profit taxes allow financial regulation constraints to be less restrictive.

We find several interesting results regarding the optimal policy tools. First, all policy tools are countercyclical. Interest rates are higher during expansions; capital and leverage regulations bind in expansion periods and are relaxed during contractions; taxes are higher during expansions when moral hazard is elevated and intermediaries have incentives to engage in excessive risk taking. Second, bond rates are higher when they are implemented with leverage regulation, because capital regulation distorts the equilibrium bond return, since it directly affects the asset composition of intermediaries. Third, optimal leverage regulation imposes a stricter requirement on equity than does the optimal capital regulation, enabling the implementation of the social optimum without explicit restrictions on the composition of assets. 


\section{Introduction}

In the aftermath of the recent financial crisis, policymakers and economists have raised several questions regarding the optimal design of monetary policy and macroprudential regulations. First, should monetary policy be used to manage financial system risks, or should financial stability objectives be left entirely to regulation (Bernanke (2010), Blanchard, Dell'Ariccia, and Mauro (2010), Svensson (2015))? Second, should monetary policy be coordinated with regulation to achieve some common macroprudential goals (Cecchetti and Kohler (2012), Macklem (2011), Yellen (2010))? Third, should financial institutions be taxed to help finance the cost of financial crises (International Monetary Fund (2010))? In this paper, we argue that monetary policy and financial regulations need to be coordinated because monetary policy affects financial intermediaries' risky investments (Altunbas, Gambacorta, and Marques-Ibane (2014)) and because strict financial regulations alone generate large welfare costs (Van den Heuvel (2009)). ${ }^{1}$ Moreover, we show that incorporating taxes in the macroprudential policy toolkit allows financial regulations to be more lenient. ${ }^{2}$

We develop a quantitative model in which financial intermediaries' investments in risky assets (i.e., risk taking) over the business cycle are influenced by both monetary policy and macroprudential policies, namely financial regulations on capital or leverage, and profit taxes. Risk taking may exceed the social optimum because intermediaries have limited liability and are partly funded through insured deposits. We focus on time-varying macroprudential policies, which alleviate the moral hazard of intermediaries during expansions, while being more lenient in recessions. ${ }^{3}$ Our main contribution is to show that the optimal policy tools need to be coordinated to deter excessive risk taking. Specifically, monetary policy rates

\footnotetext{
${ }^{1}$ A growing empirical literature documents a negative relationship between the level of interest rates and the riskiness of intermediaries' assets. Most studies (including the one cited in the text) use nominal interest rate data to establish this empirical observation, while Dell'Ariccia, Laeven, and Marquez (2014) and de Nicolò, Dell'Ariccia, Laeven, and Valencia (2010) use the real federal funds rate.

${ }^{2}$ The macroprudential role of taxes is also analyzed in Jeanne and Korinek (2013) and Keister (2016).

${ }^{3}$ There is relatively limited experience with the effectiveness of macroprudential policies. Damar and Molico (2016), Cerutti, Claessens, and Laeven (2015) and Lim, Columba, Costa, Kongsamut, Otani, Saiyid, Wezel, and $\mathrm{Wu}$ (2011) provide cross-country overviews of macroprudential policies (cyclical vs. structural, fixed vs. time-varying, broad-based vs. sectoral) and conclude that they help mitigate financial sector risks.
} 
are higher in the presence of leverage regulation compared to capital regulation. Moreover, profit taxes allow financial regulation constraints to be looser.

Our theoretical framework extends the dynamic general equilibrium model with persistent aggregate shocks and idiosyncratic uncertainty in Cociuba, Shukayev, and Ueberfeldt (2016) (henceforth, CSU) to allow for capital and leverage regulations, as well as a tax on financial intermediaries' profits. Intermediaries choose portfolios of safe bonds and risky projects. The latter are investments in the production technologies of firms and can be of two types: highrisk and low-risk projects. High-risk projects are more productive during good aggregate states and less productive during bad aggregate states compared to low-risk projects.

Intermediaries make two portfolio choices in each period. At the time of the first portfolio decision, the aggregate shock and the idiosyncratic type of intermediaries' risky projects are unknown, and investments are subject to financial regulations. At the time of the second portfolio decision, the aggregate shock is still unknown, but the type of risky projects is revealed, and intermediaries use bonds as collateral in an interbank market to adjust the scale of their risky investments. During an expansion, when aggregate productivity is expected to be high, intermediaries with high-risk projects-i.e., high-risk intermediaries - trade bonds to invest more in risky projects. These projects are attractive from a social point of view due to their high expected returns, and are attractive for intermediaries because potential losses in the event of a contraction are avoided through limited liability (Allen and Gale (2000)). Lowrisk intermediaries on the other side of the transaction accept bonds and reduce exposure to their risky projects with lower expected returns. The second portfolio choices are not subject to financial regulations. The implicit assumption is that intermediaries abide by the financial regulations at the first portfolio decision, which coincides with the quarterly public reporting of their balance sheets. Between reporting periods, intermediaries may increase their risky investments (Kelly, McGinty, and Fitzpatrick (2010)) and disregard regulations.

The rationale for incorporating collateralized interbank borrowing in the model is the empirical observation that, over the last few decades, intermediaries have increasingly used 
collateralized borrowing in interbank markets to alter their portfolio risk (Adrian and Shin (2010)). In addition, during the recent financial crisis, borrowing against collateral through the sale and repurchase market - commonly known as the repo market - came to a halt and caused major disruptions in banking (Gorton and Metrick (2012)).

We define risk taking as excessive if investments in high-risk projects in our decentralized economy exceed the social optimum, defined as the solution to a planner's problem. The policy tools used to implement the social optimum as a competitive equilibrium are interest rate policy, capital or leverage regulation, and taxes on intermediaries' profits. The interest rate policy alters the bond return, and profit taxes alter the return on intermediaries' equity. Capital regulation imposes a lower bound on intermediaries' equity to risky investment ratio, while leverage regulation imposes an upper bound on intermediaries' total assets to equity ratio. ${ }^{4}$ Moreover, all policy tools are allowed to vary over time. The state-contingent nature of our model's regulatory capital is in line with Basel III, which introduces time-variation via countercyclical capital buffers. Under Basel III, required capital may increase from 10.5 percent up to 13 percent, at the discretion of national authorities (Basel Committee on Banking Supervision (2011)). ${ }^{5}$ For symmetry, we allow our model's leverage regulation to be state-contingent, although Basel III calls for a fixed leverage ratio. ${ }^{6}$ Our paper focuses on time-variation in financial regulations and abstracts from risk weighting of capital. This modeling choice is motivated by Hellwig (2010), who argues for a thorough overhaul of capital regulation because, over time, modifications of the Basel accords designed to improve the risk calibration of assets actually enabled banks to reduce regulatory capital.

Our main result is that, in the model calibrated to the U.S. economy, either statecontingent capital or leverage regulation implements the social optimum when combined with a tax on intermediaries' profits and optimally chosen interest rate policy. To gain in-

\footnotetext{
${ }^{4}$ In our model, imposing an upper bound on intermediaries' total assets to equity ratio is equivalent to imposing an upper bound on the deposit to equity ratio (for details, see Section 2.1).

${ }^{5}$ Basel III states that a countercyclical buffer in the range of 0-2.5 percent may be imposed if national authorities judge that excessive credit growth may lead to a buildup of risk and potential future losses.

${ }^{6}$ Basel III introduces "a simple, non-risk based" leverage ratio as a supplement to capital regulation.
} 
tuition about this result, we examine a simplified version of our model with i.i.d. aggregate shocks, where we derive analytical results. Here, as in the full model, bankruptcy may occur if intermediaries do not pay the promised rate of return to depositors and use their limited liability to shield themselves from losses. We find that implementing the social optimum in a competitive equilibrium with bankruptcy requires $(i)$ either capital or leverage regulations to bind, (ii) interest rates to be higher if leverage regulation is in place and (iii) profit taxes to be weakly positive. Moreover, there is a trade-off between profit taxes and financial regulatory bounds. Implementing efficient risk taking with zero taxes requires either very high minimum regulatory capital or very low maximum leverage. For example, using parameters from our calibration, a capital requirement of about 62 percent is required to implement the social optimum if taxes are zero. A tax of 3.5 percent reduces the capital requirement to the 10.5 percent level required by Basel III regulation because the tax helps moderate the risk taking of intermediaries. The negative relationship between taxes and regulations in the optimal policy toolkit carries over to our model with persistent aggregate shocks.

To fully characterize the optimal policy tools, we calibrate our model with persistent aggregate shocks to the U.S. economy and its financial sector and examine two numerical experiments. The optimal CAP experiment implements the social optimum with interest rate policy, capital regulation and profit taxes, whereas the policy tools in the optimal LEV experiment are interest rate policy, leverage regulation and profit taxes. We find that financial regulations only bind in good aggregate states, when high-risk intermediaries have incentives to engage in excessive risk taking. Moreover, interest rates are lower in the optimal CAP experiment because capital regulation distorts the equilibrium bond return, since it directly affects the asset composition of intermediaries. Lastly, optimal leverage regulation implements the social optimum with more equity compared to optimal capital regulation, despite no explicit restrictions on the composition of assets.

We conduct additional experiments to evaluate the impact of deviating from the optimal policies. We find that lowering the policy rate has a big impact on risk taking in both 
implementations of the social optimum. Lower bond returns reduce bond purchases, the size of the balance sheet and the total amount of resources allocated to high-risk investments. Thus, risk taking and welfare are lower than optimal. In addition, we find that variations in the capital regulation bound (which restricts the equity to risky investment ratio) in the range contemplated by policymakers (i.e., from 8 percent in Basel II to 10.5 percent in Basel III) have a weak effect on risk taking in the economy. However, variations in the leverage regulation bound (which restricts the total assets to equity ratio) have a stronger impact on risk taking relative to comparable experiments with capital regulation, because bond returns are higher under leverage regulation. Another reason to prefer leverage regulation is that it is easier to implement than capital regulation, which requires assessing the riskiness of all assets on an intermediary's balance sheet. ${ }^{7}$

Our paper contributes to the growing literature on the risk taking channel of monetary policy, a term coined by Borio and Zhu (2012) to capture the impact of monetary policy on financial intermediaries' risk taking. Several recent papers study the interactions between monetary policy and macroprudential regulations in dynamic stochastic general equilibrium models in which monetary policy Taylor rules respond to indicators of financial market conditions (e.g. asset prices, credit, leverage). Loisel (2014) reviews key papers in this literature. ${ }^{8}$ In comparison, in our model, the monetary authority is assumed to influence the real interest rate on safe bonds. We abstract from changes in nominal interest rates and focus on explicitly modeling the impact of real policy rates on intermediaries' risk taking in a model with a collateralized interbank market. ${ }^{9}$

\footnotetext{
${ }^{7}$ In addition to the difficulty of assessing the risk-weights of assets, in the run-up to the recent financial crisis, intermediaries used regulatory arbitrage (e.g. they set up off-balance-sheet conduits or retained senior tranches of CDOs and CLOs on balance sheets) to reduce their capital requirements (Acharya and Schnabl (2009)). Dubecq, Mojon, and Ragot (2015) examine the impact of regulatory arbitrage, modeled as imperfect information about risk-weighted capital, on financial intermediaries' risk taking and debt risk premia.

${ }^{8}$ Papers cited in Loisel (2014) include Angeloni and Faia (2013) and Christensen, Meh, and Moran (2011), who assess the interaction between monetary policy rules and countercyclical capital regulation (which requires banks to build buffers in good times, consistent with Basel III regulation).

${ }^{9}$ Having the nominal interest rate as a policy instrument would enrich the policy insights by introducing additional trade-offs. For example, the monetary authority may choose to keep nominal interest rates low because the recovery of the economy from a recession is weak, or because inflation is falling (Bernanke (2010)). Analyzing these additional trade-offs is beyond the scope of this paper.
} 
Closely related to our paper is Collard, Dellas, Diba, and Loisel (2016), who characterize optimal interest rate policy and capital regulation in a model with limited liability and deposit insurance. The main focus of their paper is on a model in which monetary policy has no impact on bank risk taking. As a result, capital regulation and monetary policy have separate objectives: the former prevents inefficient risk taking, while the latter stabilizes business cycle fluctuations. In contrast, interest rate policy in our paper affects risk taking through the use of government bonds as collateral in the interbank market. Moreover, optimal interest rate policy alone cannot eliminate intermediaries' excessive risk taking (as shown in CSU). As a result, achieving efficient risk taking requires interest rate policy and macroprudential regulations to be coordinated.

The paper is organized as follows. Section 2 presents the decentralized environment and the social planner's problem. Section 3 presents results from a simplified version of our model in which we analytically derive the optimal monetary policy and macroprudential regulations that implement the social optimum as a competitive equilibrium. Section 4 describes the quantitative analysis and Section 5 concludes.

\section{Model Economy}

We extend the model in CSU to allow for capital and leverage regulations, as well as a tax on financial intermediaries' profits. Our goal is to examine the interaction between interest rate policy and financial regulations in controlling the risk taking of intermediaries.

The economy is populated by households, financial intermediaries, nonfinancial firms and a government. The existence of intermediaries is motivated by the assumption that households cannot invest directly in some of the economy's risky assets (Gale (2004)).

Time is discrete and infinite. Each period, the economy is subject to an exogenous aggregate shock that affects the productivity of all firms. In addition, financial intermediaries are subject to idiosyncratic shocks that determine their type. The aggregate shock $s_{t} \in$ 
$\{\bar{s}, \underline{s}\}$ follows a first-order Markov process and is persistent. The history of aggregate shocks up to time $t$ is $s^{t}$. The idiosyncratic shock $j \in\{h, l\}$ is i.i.d. across time and across financial intermediaries. Figure 1 summarizes the timing of events in our model.

\subsection{Financial Sector}

Financial intermediaries choose portfolios of safe and risky investments to maximize expected profits. Similar to CSU, intermediaries have limited liability and are partly funded through insured deposits. These features create a moral hazard problem, which makes risky investments attractive for intermediaries. Moreover, in each period, after type $j$ is revealed, intermediaries can adjust the scale of risky investments by borrowing or lending against collateral in an interbank market. The novelty of this paper relative to CSU is that we model profit taxes and financial regulations to limit intermediaries' risk taking incentives.

The risky projects of intermediaries are investments into the production technologies of firms. ${ }^{10}$ With probability $\pi_{j}$, a risky project is of type $j \in\{h, l\}$ and has productivity $q_{j}\left(s_{t}\right)$. We assume $(i)$ the probabilities, $\pi_{h}$ and $\pi_{l}=1-\pi_{h}$, are time and state invariant and known, (ii) the high-risk projects are more productive during a good aggregate state and less productive during a bad aggregate state compared with low-risk projects, $q_{h}(\bar{s})>q_{l}(\bar{s}) \geq$ $q_{l}(\underline{s})>q_{h}(\underline{s})$, and $(i i i)$ intermediaries cannot trade contingent claims on their projects.

Each period, financial intermediaries make two portfolio decisions. At the time of the first portfolio decision, the aggregate shock, $s_{t}$, and the type, $j$, are unknown and intermediaries are subject to financial regulation constraints. Intermediaries are identical and make the same portfolio investments in government bonds, $b\left(s^{t-1}\right)$, and risky projects, $k\left(s^{t-1}\right)$. At the time of the second portfolio decision, the aggregate shock $s_{t}$ is unknown, while the type $j \in\{h, l\}$ is revealed. Intermediaries are referred to as being high-risk or low-risk, based on the type $j$ of their risky projects. Intermediaries can trade bonds in an interbank market in order to adjust the amount of resources invested in the risky projects. The resulting

\footnotetext{
${ }^{10}$ For simplicity, we abstract from loans between intermediaries and firms and information asymmetries à la Bernanke and Gertler (1989). We assume intermediaries operate the firms' production technology directly.
} 
capital is $k_{j}\left(s^{t-1}\right) \equiv k\left(s^{t-1}\right)+\tilde{p}\left(s^{t-1}\right) \tilde{b}_{j}\left(s^{t-1}\right)$, where $k\left(s^{t-1}\right)$ is the initial risky investment and $\tilde{b}_{j}\left(s^{t-1}\right)$ are bonds traded at the interbank market price $\tilde{p}\left(s^{t-1}\right)$. The second portfolio decisions are not subject to financial regulation constraints. Implicitly, we assume that the first portfolio decision coincides with the quarterly public reporting of balance sheets, and intermediaries abide by the financial regulations at this time. Between reporting periods, intermediaries may increase their risky investments (Kelly, McGinty, and Fitzpatrick (2010)) and disregard regulations.

The assumption regarding the timing of the aggregate and idiosyncratic shocks is crucial for the existence of an interbank market in this model, and captures the idea that information about the riskiness of projects evolves over time. ${ }^{11}$ As a result, intermediaries adjust their portfolios, but may be constrained in their choices by the amount of bonds, $b\left(s^{t-1}\right)$, available as collateral for interbank borrowing. The need for collateral in interbank borrowing is motivated by a debt enforcement problem à la Kiyotaki and Moore (1997).

After the two portfolio decisions, the aggregate shock $s_{t}$ realizes at the beginning of period $t$. Intermediaries choose labor demand for the risky projects, $l_{j}\left(s^{t}\right)$, and produce using technology $q_{j}\left(s_{t}\right)\left[k_{j}\left(s^{t-1}\right)\right]^{\theta}\left[l_{j}\left(s^{t}\right)\right]^{1-\theta-\alpha}$, where $1-\alpha-\theta \geq 0$ and $\alpha, \theta \in[0,1]$. If $\alpha>0$ there is a fixed factor of production, whose returns are paid to equity holders. The fixed factor helps the calibrated model match U.S. financial sector data. Following production, intermediaries unable to pay the promised rate of return on deposits declare bankruptcy.

\section{Portfolio Choice in the Bond Market}

At the time of the first portfolio decision, the aggregate shock, $s_{t}$, and the type, $j$, are unknown. There is a measure $1-\pi_{m}$ of identical financial intermediaries that choose deposit demand, $d\left(s^{t-1}\right)$, safe bonds, $b\left(s^{t-1}\right)$, and risky investments, $k\left(s^{t-1}\right)$, to maximize the ex-

\footnotetext{
${ }^{11}$ If $s_{t}$ and $j$ were known at the beginning of each period, resources from households would be allocated so as to equalize intermediaries' marginal rates of return, and there would be no need for an interbank market.
} 
pected profits net of taxes given in problem $(P 1)$ subject to financial regulation constraints.

$$
\left.\begin{array}{c}
\max _{\left\{d\left(s^{t-1}\right), b\left(s^{t-1}\right), k\left(s^{t-1}\right)\right\}} \sum_{j \in\{h, l\}} \pi_{j} \sum_{s^{t} \mid s^{t-1}} \lambda\left(s^{t}\right) \cdot\left[1-\tau\left(s^{t-1}\right)\right] V_{j}\left(s^{t}\right) \\
\text { subject to: } \\
z\left(s^{t-1}\right)+d\left(s^{t-1}\right)=k\left(s^{t-1}\right)+p\left(s^{t-1}\right) b\left(s^{t-1}\right) \\
\left.V_{j}\left(s^{t}\right)=\max \left\{\begin{array}{l}
q_{j}\left(s_{t}\right)\left[k\left(s^{t-1}\right)+\tilde{p}\left(s^{t-1}\right) \tilde{b}_{j}\left(s^{t-1}\right)\right]^{\theta}\left[l_{j}\left(s^{t}\right)\right]^{1-\theta-\alpha} \\
+q_{j}\left(s_{t}\right)(1-\delta)\left[k\left(s^{t-1}\right)+\tilde{p}\left(s^{t-1}\right) \tilde{b}_{j}\left(s^{t-1}\right)\right] \\
+\left[b\left(s^{t-1}\right)-\tilde{b}_{j}\left(s^{t-1}\right)\right]-W_{j}\left(s^{t}\right) l_{j}\left(s^{t}\right)-R^{d}\left(s^{t-1}\right) d\left(s^{t-1}\right)
\end{array}\right], 0\right\} \\
\frac{z\left(s^{t-1}\right)}{k\left(s^{t-1}\right)} \geq \eta^{C A P}\left(s^{t-1}\right) \\
\frac{z\left(s^{t-1}\right)}{d\left(s^{t-1}\right)} \geq \eta^{L E V}\left(s^{t-1}\right)
\end{array}\right\}
$$

In problem $(P 1), V_{j}\left(s^{t}\right)$ are gross profits for intermediary $j$ at history $s^{t}$ and are taxed at rate, $\tau\left(s^{t-1}\right)$. Since households own the financial intermediaries, profits at history $s^{t}$ are valued at the households' marginal utility of consumption (weighted by the probability of history $\left.s^{t}\right)$, denoted by $\lambda\left(s^{t}\right)$. Intermediaries take as given $\lambda\left(s^{t}\right)$, the bond price, $p\left(s^{t-1}\right)$, the interbank market price, $\tilde{p}\left(s^{t-1}\right)$, the wage rate, $W_{j}\left(s^{t}\right)$, the return on deposits, $R^{d}\left(s^{t-1}\right)$, the tax rate, $\tau\left(s^{t-1}\right)$, the regulatory bounds, $\eta^{C A P}\left(s^{t-1}\right)$ and $\eta^{L E V}\left(s^{t-1}\right)$, the bonds traded in the interbank market, $\tilde{b}_{j}\left(s^{t-1}\right)$, the labor input, $l_{j}\left(s^{t}\right)$, and the equity chosen by households, $z\left(s^{t-1}\right) .{ }^{12}$ Note that $\tilde{b}_{j}\left(s^{t-1}\right)$ is chosen after the type, $j$, is realized, while $l_{j}\left(s^{t}\right)$ and $W_{j}\left(s^{t}\right)$ are determined after the type, $j$, and the aggregate shock, $s_{t}$, are realized.

The balance sheet of an intermediary (equation (1)) shows that portfolio investments are funded through equity, $z\left(s^{t-1}\right)$, and deposits, $d\left(s^{t-1}\right)$. Equity returns are contingent on the realization of the aggregate state in the period when they are paid, while returns on deposits are not (i.e., $V_{j}\left(s^{t}\right)$ depends on $s_{t}$, while $R^{d}\left(s^{t-1}\right)$ does not). In addition, equity returns are bounded below by zero due to the limited liability of intermediaries (i.e., $V_{j}\left(s^{t}\right)$ cannot be

\footnotetext{
${ }^{12}$ Due to limited liability and deposit insurance, financial intermediaries prefer to be funded via deposits rather than equity. We assume that equity in our model is determined by households.
} 
negative, as seen in equation (2)), while deposit returns are guaranteed by deposit insurance. The limited liability introduces an asymmetry that allows intermediaries to be profitable in good aggregate states while shielding them from losses in bad aggregate states.

Gross profits of intermediaries (equation (2)) equal revenues from investments net of payments to labor and to deposits. Note that the value of the undepreciated capital stock invested in the risky projects (i.e., $q_{j}\left(s_{t}\right)(1-\delta)\left[k\left(s^{t-1}\right)+\tilde{p}\left(s^{t-1}\right) \tilde{b}_{j}\left(s^{t-1}\right)\right]$, where $\delta$ is the depreciation rate), fluctuates with the productivity level, as in Merton (1973) and Gertler and Kiyotaki (2010), to capture the idea that while capital may not depreciate in a physical sense during contraction periods, it depreciates in an economic sense. ${ }^{13}$

We augment the model in CSU by introducing profit taxes, $\tau\left(s^{t-1}\right)$, and two types of financial regulations. Capital regulation (equation (3)) requires financial intermediaries to hold a ratio of equity to risky investment at history $s^{t-1}$ of at least $\eta^{C A P}\left(s^{t-1}\right)$. This minimum regulatory capital is state-contingent, in line with Basel III, which introduces time-variation via countercyclical capital buffers (Basel Committee on Banking Supervision (2011)). Leverage regulation (equation (4)) restricts the amount of deposit liabilities financial intermediaries are able to accept to a fraction $\frac{1}{\eta^{L E V}\left(s^{t-1}\right)}$ of equity. To understand why equation (4) is a constraint on leverage, recall that leverage is defined as the ratio of total assets to equity. Using the notation in Problem $(P 1)$, leverage is $\frac{k\left(s^{t-1}\right)+p\left(s^{t-1}\right) b\left(s^{t-1}\right)}{z\left(s^{t-1}\right)}=$ $\frac{z\left(s^{t-1}\right)+d\left(s^{t-1}\right)}{z\left(s^{t-1}\right)}=1+\frac{d\left(s^{t-1}\right)}{z\left(s^{t-1}\right)}$. Hence, leverage regulation puts an upper bound on the ratio of deposit borrowing to equity. The Basel III regulation introduces a fixed leverage ratio as a supplement to capital regulation. In our framework, we allow leverage regulation to be state-contingent. We show that either state-contingent capital or leverage regulation implements the social optimum when combined with a tax on intermediaries' profits and optimally chosen interest rate policy.

\footnotetext{
${ }^{13}$ For suporting empirical evidence, see Ramey and Shapiro (2001) and Eisfeldt and Rampini (2006).
} 


\section{Portfolio Adjustments via the Interbank Market}

At the time of the second portfolio decision, the aggregate shock, $s_{t}$, is unknown, while the type, $j \in\{h, l\}$, is known. High-risk $(j=h)$ and low-risk $(j=l)$ intermediaries choose whether to adjust the riskiness of their portfolios by trading bonds, $\tilde{b}_{j}\left(s^{t-1}\right)$, in an interbank market. Intermediaries choose $\tilde{b}_{j}\left(s^{t-1}\right)$ and, implicitly, $k_{j}\left(s^{t-1}\right) \equiv k\left(s^{t-1}\right)+\tilde{p}\left(s^{t-1}\right) \tilde{b}_{j}\left(s^{t-1}\right)$ to solve problem $(P 2)$, taking as given the initial portfolio decisions, $d\left(s^{t-1}\right), b\left(s^{t-1}\right)$, $k\left(s^{t-1}\right)$, as well as $\lambda\left(s^{t}\right), p\left(s^{t-1}\right), \tilde{p}\left(s^{t-1}\right), W_{j}\left(s^{t}\right), R^{d}\left(s^{t-1}\right), \tau\left(s^{t-1}\right), l_{j}\left(s^{t}\right)$, and $z\left(s^{t-1}\right)$.

$$
\begin{gathered}
\max _{\left\{\tilde{b}_{j}\left(s^{t-1}\right), k_{j}\left(s^{t-1}\right)\right\}} \sum_{s^{t} s^{t-1}} \lambda\left(s^{t}\right) \cdot\left[1-\tau\left(s^{t-1}\right)\right] V_{j}\left(s^{t}\right) \\
\text { subject to: }-\frac{k\left(s^{t-1}\right)}{\tilde{p}\left(s^{t-1}\right)} \leq \tilde{b}_{j}\left(s^{t-1}\right) \leq b\left(s^{t-1}\right)
\end{gathered}
$$

where $V_{j}\left(s^{t}\right)$ is defined in equation (2). Inada conditions guarantee that $k_{j}\left(s^{t-1}\right) \equiv k\left(s^{t-1}\right)+$ $\tilde{p}\left(s^{t-1}\right) \tilde{b}_{j}\left(s^{t-1}\right)>0$, and hence the only potentially binding constraint in problem $(P 2)$ is $\tilde{b}_{j}\left(s^{t-1}\right) \leq b\left(s^{t-1}\right) \cdot{ }^{14}$ Here, $\tilde{b}_{j}\left(s^{t-1}\right)$ can be interpreted as sales of bonds or, alternatively, as repurchasing agreements (repos). ${ }^{15}$ For this reason, we use the terms interbank market and repo market interchangeably. As in CSU, we abstract from haircuts on collateral.

The capital and leverage regulation constraints in (3) and (4) are not imposed in problem $(P 2)$. Our implicit assumption is that intermediaries report profits and pay profit taxes to the government, but they need not reveal all the details of their balance sheet throughout the period. Indeed, there is evidence that intermediaries lower their risky investments right before the quarterly public reporting of their balance sheets, and then increase them in the

\footnotetext{
${ }^{14}$ The assumption that interbank (repo) borrowing is collateralized, $\tilde{b}_{j}\left(s^{t-1}\right) \leq b\left(s^{t-1}\right)$, is motivated by a debt enforcement problem à la Kiyotaki and Moore (1997). Namely, lenders in the interbank market cannot force borrowers to repay debts unless these debts are secured by collateral.

${ }^{15}$ While we model $\tilde{b}_{j}\left(s^{t-1}\right)$ as bond sales, incorporating explicitly the repurchase of bonds - which is typical in a repo agreement - would yield identical results. Specifically, if no bankruptcy occurs, then intermediaries have the resources necessary to repurchase the bonds from the counterparty. This simply amounts to a reshuffling of assets among intermediaries before profits are paid as returns to equity holders. When some intermediaries go bankrupt, they are unable to repurchase the bonds and the counterparty keeps them, as is true in the data. Equity holders receive no returns from bankrupt intermediaries. In either case, payments to equity holders are identical regardless of whether we model the repurchase of bonds or not.
} 
middle of successive quarters (Kelly, McGinty, and Fitzpatrick (2010)).

Our model is consistent with evidence that repos are an important margin of balance sheet adjustment by intermediaries (Adrian and Shin (2010)) and that repos allow participants to "hedge against market risk exposures arising from other activities" (Financial Stability Board (2012)). In our model, repo borrowing is socially beneficial as it reallocates resources towards intermediaries who are expected to be more productive. In expansions, high-risk intermediaries lower their bond holdings to invest more in their risky projects. In contractions, low-risk intermediaries make similar changes to their portfolios.

While repos are beneficial, they may enable intermediaries to take advantage of their limited liability and overinvest in risky projects. More bond purchases at the time of the first portfolio decision make balance sheets seem safer, but may later lead to increased risk taking through collateralized borrowing. Although intermediaries start out as identical each period, the funds they receive from households vary with the aggregate state, allowing for interesting model dynamics, such as sustained high investments in high-risk projects.

\section{Labor Demand and Production}

After the two portfolio decisions, the aggregate shock, $s_{t} \in\{\bar{s}, \underline{s}\}$, is realized. Financial intermediaries choose labor demand, $l_{j}\left(s^{t}\right)$, to equate the wage rate with the marginal product of labor, i.e., $W_{j}\left(s^{t}\right)=(1-\theta-\alpha) q_{j}\left(s_{t}\right)\left[k_{j}\left(s^{t-1}\right)\right]^{\theta}\left[l_{j}\left(s^{t}\right)\right]^{-\theta-\alpha}$. Production takes place, returns on assets are paid and bankruptcy may occur.

We note that labor is an essential input into production. If we abstract from labor, then expected returns on financial sector equity in our model are larger than expected returns on deposits, pushing households to choose zero deposits, which is counterfactual. We assume the labor input is chosen after the intermediaries know $j$ and $s_{t}$, for computational simplicity. 


\subsection{Nonfinancial sector}

There is a measure $\pi_{m}$ of identical nonfinancial firms that choose capital, $k_{m}\left(s^{t-1}\right)$, and labor, $l_{m}\left(s^{t}\right)$, to maximize profits.

$$
\begin{gathered}
\max _{\left\{k_{m}\left(s^{t-1}\right), l_{m}\left(s^{t}\right)\right\}}\left\{y_{m}\left(s^{t}\right)+q_{m}\left(s_{t}\right)(1-\delta) k_{m}\left(s^{t-1}\right)-R^{m}\left(s^{t}\right) k_{m}\left(s^{t-1}\right)-W_{m}\left(s^{t}\right) l_{m}\left(s^{t}\right)\right\} \\
\text { subject to: } y_{m}\left(s^{t}\right)=q_{m}\left(s_{t}\right)\left[k_{m}\left(s^{t-1}\right)\right]^{\theta}\left[l_{m}\left(s^{t}\right)\right]^{1-\theta}
\end{gathered}
$$

Here, capital is funded entirely through household equity, $k_{m}\left(s^{t-1}\right)=M\left(s^{t-1}\right) / \pi_{m}$, the wage rate is $W_{m}\left(s^{t}\right)$, and the return to capital (equity), $R^{m}\left(s^{t}\right)$, depends on the productivity of the technology, $q_{m}\left(s_{t}\right)$, which satisfies: $q_{h}(\bar{s}) \geq q_{m}(\bar{s})>q_{l}(\bar{s}) \geq q_{l}(\underline{s})>q_{m}(\underline{s})>q_{h}(\underline{s})$.

The nonfinancial sector is introduced to allow our model to be consistent with U.S. data, showing a high equity to deposit ratio for households and a low equity to deposit ratio in the financial sector, and to match the relative importance of the two sectors in U.S. production.

\subsection{Households}

There is a measure one of identical households who maximize expected utility.

$$
\begin{aligned}
& \max _{\left\{C\left(s^{t}\right), D_{h}\left(s^{t}\right), Z\left(s^{t}\right), M\left(s^{t}\right)\right\}} \sum_{t=0}^{\infty} \sum_{s^{t}} \beta^{t} \varphi\left(s^{t}\right) \log C\left(s^{t}\right) \\
& \text { subject to: } w\left(s^{t}\right)= R^{d}\left(s^{t-1}\right) D_{h}\left(s^{t-1}\right)+R^{z}\left(s^{t}\right) Z\left(s^{t-1}\right)+R^{m}\left(s^{t}\right) M\left(s^{t-1}\right) \\
&+\pi_{m} W_{m}\left(s^{t}\right)+\left(1-\pi_{m}\right) \pi_{l} W_{l}\left(s^{t}\right)+\left(1-\pi_{m}\right) \pi_{h} W_{h}\left(s^{t}\right)+T\left(s^{t}\right) \\
& w\left(s^{t}\right)= C\left(s^{t}\right)+M\left(s^{t}\right)+D_{h}\left(s^{t}\right)+Z\left(s^{t}\right)
\end{aligned}
$$

Here, $\beta$ is the discount factor and $\varphi\left(s^{t}\right)$ is the probability of history $s^{t}$. At the beginning of period $t$, the aggregate state $s_{t}$ is revealed, and household wealth, $w\left(s^{t}\right)$, composed of returns on previous period investments, wage income and lump-sum taxes $\left(T\left(s^{t}\right)<0\right)$ or transfers $\left(T\left(s^{t}\right) \geq 0\right)$ from the government, is realized. Households spend their wealth on 
consumption, $C\left(s^{t}\right)$, and investments that will pay returns next period.

Investments take the form of deposits, financial sector equity and nonfinancial sector equity. Deposits, $D_{h}\left(s^{t-1}\right)$, earn a fixed return, $R^{d}\left(s^{t-1}\right)$, which is guaranteed by deposit insurance. Equity invested in the financial sector, $Z\left(s^{t-1}\right)$, is a risky investment that gives households a state-contingent claim to the profits of the intermediaries. The return per unit of equity is $R^{z}\left(s^{t}\right)=\frac{1}{z\left(s^{t-1}\right)} \sum_{j \in\{h, l\}} \pi_{j}\left[1-\tau\left(s^{t-1}\right)\right] V_{j}\left(s^{t}\right)$. Similarly, the equity invested in the nonfinancial sector, $M\left(s^{t-1}\right)$, receives a state-contingent return, $R^{m}\left(s^{t}\right)$. An interior solution in which households invest in all three assets requires that expected returns on deposits and equity are equalized. Formally, $\sum_{s^{t+1} \mid s^{t}} \frac{\beta^{t+1} \varphi\left(s^{t+1}\right)}{C\left(s^{t+1}\right)}\left[R^{z}\left(s^{t+1}\right)-R^{d}\left(s^{t}\right)\right]=$ $\sum_{s^{t+1} \mid s^{t}} \frac{\beta^{t+1} \varphi\left(s^{t+1}\right)}{C\left(s^{t+1}\right)}\left[R^{z}\left(s^{t+1}\right)-R^{m}\left(s^{t+1}\right)\right]=0$.

Each household supplies one unit of labor inelastically. We assume that labor markets are segmented. Fraction $\pi_{m}$ of a household's time is spent working in the nonfinancial sector, and fraction $1-\pi_{m}$ is spent in the financial sector. Within the financial sector, a household's time is split between high-risk and low-risk intermediaries according to shares $\pi_{j}$, where $\pi_{h}+\pi_{l}=1$. Given that there are measure one of households and measure one of firms, labor supplied to each firm is one unit for any realization of the aggregate state.

\subsection{Government}

The government issues bonds that financial intermediaries hold as an investment or use as a medium of exchange in the repo market. The government sells bonds, $B\left(s^{t-1}\right)$, at price, $p\left(s^{t-1}\right)$, and deposits the proceeds with financial intermediaries. ${ }^{16}$ Each intermediary purchases risk-free assets $b\left(s^{t-1}\right)=B\left(s^{t-1}\right) /\left(1-\pi_{m}\right)$ and receives $D_{g}\left(s^{t-1}\right) /\left(1-\pi_{m}\right)$ of government deposits, where $D_{g}\left(s^{t-1}\right)=p\left(s^{t-1}\right) B\left(s^{t-1}\right)$. To guarantee the return on deposits the government provides deposit insurance at zero price, which is financed through household taxation and taxes on intermediaries' profits. ${ }^{17}$ The government balances its bud-

\footnotetext{
${ }^{16}$ Alternatively, the proceeds from the bond sales could be transferred to households.

${ }^{17}$ Pennacchi (2006, pg. 14) documents that, since 1996 and prior to the crisis, deposit insurance has been essentially free for U.S. banks. In our model, the assumption of a zero price of deposit insurance is not
} 
get after production takes place at the beginning of period $t .^{18}$

$$
T\left(s^{t}\right)+B\left(s^{t-1}\right)+\Delta\left(s^{t}\right)=R^{d}\left(s^{t-1}\right) D_{g}\left(s^{t-1}\right)+\tau\left(s^{t-1}\right) \cdot\left(1-\pi_{m}\right) \sum_{j \in\{h, l\}} \pi_{j} V_{j}\left(s^{t}\right)
$$

Here, $\Delta\left(s^{t}\right)$ is deposit insurance necessary to guarantee the return on deposits, $R^{d}\left(s^{t-1}\right)$. Given limited liability, intermediaries may pay a deposit return smaller than $R^{d}\left(s^{t-1}\right)$, which ensures that they break even, while the remainder is covered by deposit insurance.

\subsection{Market clearing}

The labor market clearing conditions state that labor demanded by financial intermediaries and nonfinancial firms equals labor supplied by households: $\pi_{m} l_{m}\left(s^{t}\right)=\pi_{m}$ and $\left(1-\pi_{m}\right) \pi_{j} l_{j}\left(s^{t}\right)=\left(1-\pi_{m}\right) \pi_{j}$ for each $j \in\{h, l\}$. This implies $l_{m}\left(s^{t}\right)=l_{h}\left(s^{t}\right)=l_{l}\left(s^{t}\right)=1$.

The goods market clearing condition equates total output produced with aggregate consumption and investment. Output produced by nonfinancial firms is $\pi_{m} q_{m}\left(s^{t}\right)\left[k_{m}\left(s^{t-1}\right)\right]^{\theta}$, while output produced by financial firms is $\left(1-\pi_{m}\right) \sum_{j \in\{l, h\}} \pi_{j} q_{j}\left(s^{t}\right)\left[k_{j}\left(s^{t-1}\right)\right]^{\theta}$, where $k_{j}\left(s^{t-1}\right)$ are resources allocated to the risky projects after repo market trading.

$$
\begin{aligned}
C\left(s^{t}\right)+M\left(s^{t}\right)+D_{h}\left(s^{t}\right)+Z\left(s^{t}\right)= & \pi_{m} q_{m}\left(s_{t}\right)\left[\left[k_{m}\left(s^{t-1}\right)\right]^{\theta}+(1-\delta) k_{m}\left(s^{t-1}\right)\right] \\
& +\left(1-\pi_{m}\right) \sum_{j \in\{l, h\}} \pi_{j} q_{j}\left(s_{t}\right)\left[\left[k_{j}\left(s^{t-1}\right)\right]^{\theta}+(1-\delta) k_{j}\left(s^{t-1}\right)\right]
\end{aligned}
$$

There are four financial market clearing conditions. Deposits demanded by intermediaries equal deposits from households and the government: $D_{h}\left(s^{t-1}\right)+D_{g}\left(s^{t-1}\right)=D\left(s^{t-1}\right)=$ $\left(1-\pi_{m}\right) d\left(s^{t-1}\right)$. Bond sales by the government equal the bond purchases by financial intermediaries: $B\left(s^{t-1}\right)=\left(1-\pi_{m}\right) b\left(s^{t-1}\right)$. Interbank repo market trades between the dif-

crucial. What matters is that the insurance is not priced in a way to eliminate moral hazard. This means, for example, that deposit insurance cannot be contingent on the portfolio decisions of the intermediaries.

${ }^{18}$ We concentrate on new issuance of (one period) bonds and abstract from outstanding bonds for computational reasons. Considering the valuation effects of interest rate policy in the presence of outstanding bonds may be an interesting extension of the model. 
ferent types of intermediaries must balance: $\sum_{j \in\{l, h\}} \pi_{j} \tilde{b}_{j}\left(s^{t-1}\right)=0$. Lastly, total equity invested by households in the financial and nonfinancial sectors is distributed over the firms: $M\left(s^{t-1}\right)=\pi_{m} k_{m}\left(s^{t-1}\right)$ and $Z\left(s^{t-1}\right)=\left(1-\pi_{m}\right) z\left(s^{t-1}\right)$.

\subsection{Social Planner}

We examine a social planner's problem to determine the efficient allocation of resources. We maintain the assumption on the timing of shocks to allow the social planner's environment to be comparable to the decentralized one. In a slight abuse of language, we refer to the technologies available to the social planner as belonging to financial and nonfinancial sectors.

At the beginning of period $t$, the aggregate shock, $s_{t}$, is revealed and production takes place using capital that the planner has allocated to the different technologies of production: $k_{m}\left(s^{t-1}\right)$ for the nonfinancial sector and $k_{h}\left(s^{t-1}\right)$ and $k_{l}\left(s^{t-1}\right)$ for the high-risk and low-risk technologies of the financial sector. Output is then split between consumption and capital to be used in production at $t+1$. At the time of this decision, the type, $j$, and the aggregate shock, $s_{t+1}$, are unknown, and the social planner allocates $k_{b}\left(s^{t}\right)$ resources to all financial sector technologies. Once $j$ is revealed, the social planner reallocates resources between the high-risk and low-risk technologies. ${ }^{19}$

\footnotetext{
${ }^{19}$ We note that in the competitive equilibrium, the financial regulator doesn't know type $j$ and doesn't see the reallocation via repos between intermediaries.
} 
The social planner (SP) solves the problem below.

$$
\max E \sum_{t=0}^{\infty} \beta^{t} \log C\left(s^{t}\right)
$$

subject to:

$$
\begin{aligned}
C\left(s^{t}\right)+\pi_{m} k_{m}\left(s^{t}\right)+\left(1-\pi_{m}\right) k_{b}\left(s^{t}\right) & =\pi_{m} q_{m}\left(s_{t}\right)\left[\left[k_{m}\left(s^{t-1}\right)\right]^{\theta}+(1-\delta) k_{m}\left(s^{t-1}\right)\right] \\
& +\left(1-\pi_{m}\right) \sum_{j \in\{h, l\}} \pi_{j} q_{j}\left(s_{t}\right)\left[\left[k_{j}\left(s^{t-1}\right)\right]^{\theta}+(1-\delta) k_{j}\left(s^{t-1}\right)\right] \\
k_{l}\left(s^{t}\right) & =k_{b}\left(s^{t}\right)-\frac{\pi_{h}}{\pi_{l}} n\left(s^{t}\right) \\
k_{h}\left(s^{t}\right) & =k_{b}\left(s^{t}\right)+n\left(s^{t}\right)
\end{aligned}
$$

Here, $n\left(s^{t}\right)$ are resources given to (or taken from) each high-risk production technology, and $\frac{\pi_{h}}{\pi_{l}} n\left(s^{t}\right)$ are resources taken away from (or given to) each low-risk technology. Resources flow towards intermediaries who are expected to be more productive, i.e., high-risk intermediaries during expansion periods and low-risk intermediaries during contractions.

\subsection{Government Policies}

The government's objective is to find policy tools that implement the social optimum as a competitive equilibrium. By implementation we mean finding the interest rate policy, $1 / p\left(s^{t}\right)$, the regulatory bounds, $\eta^{C A P}\left(s^{t}\right)$ or $\eta^{L E V}\left(s^{t}\right)$, and the profit tax, $\tau\left(s^{t}\right)$, such that

the allocations in the competitive equilibrium with $\left\{1 / p\left(s^{t}\right), \eta^{C A P}\left(s^{t}\right), \eta^{L E V}\left(s^{t}\right), \tau\left(s^{t}\right)\right\}$ coincide with those from the social planner's problem.

\section{Results from a Simplified Version of the Model}

In this section, we consider a simplified version of our full model from Section 2, which allows us to derive analytically the policy tools that implement the social optimum. Moreover, we discuss implications for the full model. 
Assumptions $A 1$ : (i) The aggregate productivity shock, $s_{t}$, is i.i.d. The probability of the good aggregate state, $\bar{s}$, is $\phi$ and the probability of the bad aggregate state, $\underline{s}$, is $1-\phi$. (ii) Households are risk neutral. (iii) Depreciation is full, $\delta=1$. (iv) There is no fixed factor in financial intermediaries' production, $\alpha=0$. $(v)$ Productivity levels satisfy $q_{h}(\bar{s})>q_{l}(\bar{s})=q_{l}(\underline{s})>q_{h}(\underline{s})$. Moreover, high-risk projects have higher expected productivity than low-risk projects, $\phi q_{h}(\bar{s})+(1-\phi) q_{h}(\underline{s})>q_{l}(\bar{s})=q_{l}(\underline{s})$.

Proposition 1 shows that bankruptcy may occur in equilibrium. Intermediaries declare bankruptcy if they are unable to pay the promised rate of return to depositors.

Proposition 1 Under assumption $A 1(v)$, in a competitive equilibrium with an active interbank market, either there is no bankruptcy, or only high-risk intermediaries are bankrupt in a bad aggregate state.

Proof. See Appendix A.

The policy tools that implement the social optimum depend on whether or not there is bankruptcy in the competitive equilibrium. We analyze these two cases separately.

Proposition 2 characterizes the policy tools that implement the social optimum as a competitive equilibrium with no bankruptcy and shows that financial intermediaries need sufficiently high equity to avoid bankruptcy.

Proposition 2 Under assumptions A1, if the allocation in a competitive equilibrium with no bankruptcy coincides with the social planner's allocation, then $(i)$ the capital and leverage regulations do not bind, (ii) the interest rate policy is $\frac{1}{p\left(s^{t}\right)}=\frac{1}{\beta}$ and (iii) the tax on intermediaries' profits is zero. In addition, (iv) the intermediaries' equity to risky capital ratio satisfies: $\frac{z\left(s^{t}\right)}{k\left(s^{t}\right)}>1-\left(\phi \frac{q_{h}(\bar{s})}{q_{h}(\underline{s})}+1-\phi\right)^{-1}$.

Proof. See Appendix A.

Proposition 2 shows that, with enough equity, the moral hazard of financial intermediaries is reduced and there is no bankruptcy, as most of the intermediaries' liabilities are statecontingent. As a result, the social optimum can be implemented with a single policy tool, 
the interest rate policy, while financial regulations or taxes are not needed. In addition, the interest rate policy is unique and equal to $\beta^{-1}$. This result is similar to CSU. To get an idea of how much equity high-risk financial intermediaries need to avoid bankruptcy, we perform back of the envelope calculations using parameters in the range we estimate in our calibration section. For $\phi=0.95$, and $\frac{q_{h}(\bar{s})}{q_{h}(\underline{s})}=2.6$, we find $\frac{z\left(s^{t}\right)}{k\left(s^{t}\right)}>\frac{z\left(s^{t}\right)}{k_{h}\left(s^{t}\right)} \geq 0.60$. Namely, high-risk financial intermediaries require an equity to capital ratio of 60 percent to not default. When we calibrate our full model from Section 2 to match the lower equity levels observed in U.S. data, the model features bankruptcy.

Proposition 3 characterizes the policy tools that implement the social optimum as a competitive equilibrium with bankruptcy of high-risk intermediaries.

Proposition 3 Under assumptions A1, different combinations of policy tools implement the social optimum as a competitive equilibrium with bankruptcy. First, binding capital regulation, interest rate policy $\frac{1}{p\left(s^{t}\right)}<\frac{1}{\beta}$, and profit taxes $\tau\left(s^{t}\right) \geq 0$ implement the social optimum. Alternatively, binding leverage regulation, interest rate policy $\frac{1}{p\left(s^{t}\right)}=\frac{1}{\beta}$, and profit taxes $\tau\left(s^{t}\right) \geq 0$ implement the social optimum. In either case, there is a trade-off between taxes and financial regulations. Implementations with positive taxes allow for smaller financial regulatory bounds, i.e., $\eta^{C A P}\left(s^{t}\right)$ or $\eta^{L E V}\left(s^{t}\right)$, than implementations with zero taxes.

Proof. See Appendix $A$.

There are several important implications from Proposition 3. First, either binding capital regulation or binding leverage regulation are necessary to reduce the moral hazard of highrisk intermediaries and to implement the social optimum in a competitive equilibrium with bankruptcy. ${ }^{20}$ Second, taxes are not needed to implement the social optimum, but if used, they allow for looser financial regulation constraints. Indeed, in the proof of Proposition 3, we show that the social optimum can be implemented with interest rate policy and combinations

\footnotetext{
${ }^{20}$ The proof of Proposition 3 shows that if bankruptcy is possible at time $t$, then financial regulation binds at $t-1$. We conjecture that regulation binds in expansions, because the aggregate state may switch, leading high-risk intermediaries to default. We confirm this conjecture in our quantitative analysis (Section 4).
} 
of profit taxes and financial regulations that satisfy equation (5):

$$
\frac{1}{1-\tau\left(s^{t}\right)}=Q_{1}^{i}+Q_{2}^{i} \frac{1}{\eta^{i}\left(s^{t}\right)}, i \in\{C A P, L E V\}
$$

where the coefficients $Q_{1}^{i}, Q_{2}^{i}$ for $i \in\{C A P, L E V\}$ are functions of parameters $\phi, \theta, \pi_{j}, q_{j}(\bar{s})$ and $q_{j}(\underline{s})$ for $j \in\{h, l\} .{ }^{21}$ Since $Q_{1}^{i}>0, Q_{2}^{i}>0$, for $i \in\{C A P, L E V\}$, it is easy to show that higher taxes lower the financial regulatory bounds, i.e., $\frac{\partial \eta^{C A P}\left(s^{t}\right)}{\partial \tau\left(s^{t}\right)}<0$ and $\frac{\partial \eta^{L E V}\left(s^{t}\right)}{\partial \tau\left(s^{t}\right)}<0$.

To understand the quantitative trade-off between taxes and financial regulations, we use the parameters from our calibration (see Section 4.1) to show that if taxes are zero, the minimum regulatory capital needed to implement the social optimum is very high, i.e., $\eta^{C A P}=\frac{Q_{2}^{C A P}}{1-Q_{1}^{C A P}}=62$ percent. However, a small tax rate of 3.55 percent reduces the minimum regulatory capital needed to implement the social optimum to the Basel III level, i.e., $\eta^{C A P}=\frac{Q_{2}^{C A P}}{\frac{1}{1-0.0355}-Q_{1}^{C A P}}=10.5$ percent. Alternatively, suppose the social optimum is implemented with interest rate policy and combinations of profit taxes and leverage regulation that satisfy equation (5). Then, a zero tax requires a very low maximum leverage, i.e., $\frac{1}{\eta^{L E V}}=\frac{1-Q_{1}^{L E V}}{Q_{2}^{L E V}}=0.65$, whereas a small tax rate of 3.55 percent allows for higher leverage, i.e., $\frac{1}{\eta^{L E V}}=\frac{\frac{1}{1-0.0355}-Q_{1}^{L E V}}{Q_{2}^{L E V}}=8.75$, to implement the social optimum.

Lastly, Proposition 3 shows that the optimal interest rate policy varies with the financial regulation in place. In particular, interest rates are higher under leverage regulation than under capital regulation. To understand this result, note that under assumptions $A 1$, the interbank market bond return, $1 / \tilde{p}\left(s^{t}\right)$-which influences the composition of intermediaries' portfolios after repo trades - is equated with $\beta^{-1}$, the expected return on investments in the social planner's problem. Capital regulation introduces a wedge between the equilibrium bond return and the interbank market bond return, i.e., $1 / p\left(s^{t}\right)<1 / \tilde{p}\left(s^{t}\right)$, because it directly affects the amount of bonds intermediaries purchase. In contrast, leverage regulation

\footnotetext{
${ }^{21}$ The proof of Proposition 3 shows that: $Q_{1}^{L E V}=\pi_{l}+\phi \pi_{h} \frac{q_{h}(\bar{s})}{\phi q_{h}(\bar{s})+(1-\phi) q_{h}(\underline{s})}, Q_{2}^{L E V}=\frac{\phi \pi_{h}(1-\phi)\left[q_{h}(\bar{s})-q_{h}(\underline{s})\right]}{\phi q_{h}(\bar{s})+(1-\phi) q_{h}(\underline{s})}$, $Q_{1}^{C A P}=\pi_{l}+\phi \pi_{h}$ and $Q_{2}^{C A P}=\phi \pi_{h}(1-\phi)\left[q_{h}(\bar{s})-q_{h}(\underline{s})\right] \frac{\left[\phi q_{h}(\bar{s})+(1-\phi) q_{h}(\underline{s})\right]^{\frac{\theta}{1-\theta}}}{\sum_{j} \pi_{j}\left[\phi q_{j}(\bar{s})+(1-\phi) q_{j}(\underline{s})\right]^{\frac{1}{1-\theta}}}$.
} 
restricts the composition of intermediaries' liabilities (but not the assets), and doesn't distort the bond return, i.e., $1 / p\left(s^{t}\right)=1 / \tilde{p}\left(s^{t}\right)$. It follows that the interest rate policy is $\beta^{-1}$ if the social optimum is implemented with leverage regulation, or less than $\beta^{-1}$ if it is implemented with capital regulation (for analytical details, see the proof of Proposition 3).

\section{Quantitative Analysis}

We calibrate the model to match key features of the U.S. economy and its financial sector. We solve the model numerically and characterize the policy tools that implement the social optimum in our decentralized economy. We then perform experiments to quantify the impact of deviating from the optimal policies on intermediaries' risk taking and the macroeconomy. We define risk taking as the percentage deviation in the resources invested in the highrisk projects in a competitive equilibrium, i.e., $k_{h}^{C E}\left(s^{t}\right)$, relative to the social planner, i.e., $k_{h}^{S P}\left(s^{t}\right)$. Formally, $r\left(s^{t}\right)=\frac{k_{h}^{C E}\left(s^{t}\right)-k_{h}^{S P}\left(s^{t}\right)}{k_{h}^{S P}\left(s^{t}\right)} \cdot 100$, where a positive value of $r\left(s^{t}\right)$ indicates excessive risk taking in the competitive equilibrium, while a negative value indicates too little risk taking. We also report an aggregate measure of risk taking, defined as an average over expansions and contractions, i.e., $r \equiv E\left[r\left(s^{t}\right)\right]$. To quantify the macroeconomic impact of suboptimal policies, we use a standard welfare measure, the lifetime consumption equivalent (LTCE), defined as the percentage decrease in the planner's consumption required to give consumers the same welfare as the consumption from the competitive equilibrium.

\subsection{Calibration}

We parameterize the model to the U.S. economy, similar to CSU. Specifically, we identify our model's total output with the U.S. business sector value added and our model's nonfinancial sector with the U.S. corporate nonfinancial sector. ${ }^{22}$

\footnotetext{
${ }^{22}$ We treat the remainder of the U.S. business sector (the corporate financial and the noncorporate businesses) as the model's financial intermediation sector. In U.S. data, noncorporate businesses are strongly dependent on the financial sector for funding. In the past three decades, bank loans and mortgages were 60 to 80 percent of noncorporate businesses' liabilities. For simplicity, we do not model these loans, and assume
} 
Table 1 reports the calibrated discount factor, $\beta$, the capital share, $\theta$, the aggregate shock transition matrix, $\Phi$, and the fraction of high-risk intermediaries, $\pi_{h}$. The remaining parameters, $Q \equiv\left\{\pi_{m}, \alpha, \delta, q_{h}(\underline{s}), q_{m}(\bar{s}), q_{m}(\underline{s}), q_{l}(\bar{s}), q_{l}(\underline{s})\right\}$, are jointly estimated to match eight U.S. data moments using problem (P3). Table 2 reports the matched moments and the estimated parameters.

$$
\begin{aligned}
Q^{*}= & \arg \min _{Q} \sum_{i=1}^{8}\left(\frac{\Omega_{i}-\tilde{\Omega}_{i}}{\tilde{\Omega}_{i}}\right)^{2} \\
\text { s.t. }: & q_{h}(\underline{s})<q_{m}(\underline{s})<q_{l}(\underline{s}) \leq q_{l}(\bar{s})<q_{m}(\bar{s}) \leq q_{h}(\bar{s})=1 \text { and } \\
& \Omega_{i} \text { is implied in a competitive equilibrium, given policy tools } \Lambda^{*}, \\
& \text { where } \Lambda^{*}\left(s^{t-1}\right) \equiv\left\{p^{*}\left(s^{t-1}\right), \eta^{C A P}=0.08, \eta^{L E V}=0, \tau=0\right\}
\end{aligned}
$$

In problem $(P 3), \Omega_{i}$ is a model moment, $\tilde{\Omega}_{i}$ is the corresponding data moment, and the productivity parameters are ordered as discussed in Section 2, with the productivity of the high-risk intermediary in the good aggregate state normalized to unity. Moreover, the policy tools are given in $\Lambda^{*}\left(s^{t-1}\right)$, where the values for $\eta^{C A P}, \eta^{L E V}$, and $\tau$ are set to capture the Basel II capital regulation, and where $p^{*}\left(s^{t-1}\right)$ solves problem $(P 4) .^{23}$

$$
\begin{aligned}
& p^{*}\left(s^{t-1}\right)=\arg \max _{p\left(s^{t-1}\right)} \sum_{t=0}^{\infty} \sum_{s^{t}} \beta^{t} \varphi\left(s^{t}\right) \log C\left(s^{t}\right) \\
& \text { s.t.: } C\left(s^{t}\right) \text { is part of a competitive equilibrium given parameters } Q^{*}, \\
& \text { and policy tools } \Lambda\left(s^{t-1}\right)=\left\{p\left(s^{t-1}\right), \eta^{C A P}=0.08, \eta^{L E V}=0, \tau=0\right\}
\end{aligned}
$$

Table 2 shows that the model matches the data moments well. The first three data moments pin down $\pi_{m}, \alpha$ and $\delta$, respectively. We note that $\delta$ is chosen so that our model's

that intermediaries are endowed with the production technology of noncorporate businesses.

${ }^{23}$ Solving problem $(P 3)$ involves a two-step procedure as in CSU, because the model is nonlinear and the initial guess is very important in finding a competitive equilibrium. Given $\eta^{C A P}=8 \%, \eta^{L E V}=0, \tau=0$, an initial set of parameter values, call it $Q_{1}^{*}$, and an initial guess for our competitive equilibrium allocation (e.g. the social planner allocation), we find the optimal bond price, $p_{1}^{*}$, that solves problem $(P 4)$. Then, given $p_{1}^{*}$, we find $Q_{2}^{*}$ that solves problem $(P 3)$. We continue this iterative process until convergence is achieved. 
stochastic depreciation rate, $\frac{\pi_{m} q_{m, t} \delta k_{m, t}+\left(1-\pi_{m}\right)\left(\pi_{h} q_{h, t} \delta k_{h, t}+\pi_{l} q_{l, t} \delta k_{l, t}\right)}{\pi_{m} k_{m, t}+\left(1-\pi_{m}\right)\left(\pi_{h} k_{h, t}+\pi_{l} k_{l, t}\right)}$, matches the data. The remaining moments help pin down the productivity parameters. Note that low-risk projects are estimated to be virtually riskless, while high-risk projects have a large variance of returns. This suggests that the moral hazard problem is important for high-risk intermediaries.

\subsection{Analytical Results and Simulations from the Full Model}

We show analytically that different combinations of policy tools-i.e., either $\left(p, \eta^{C A P}, \tau\right)$ or $\left(p, \eta^{L E V}, \tau\right)$-implement the social optimum as a competitive equilibrium. We simulate the model and discuss the key characteristics of the policy tools. Lastly, we vary the interest rate policy, the regulatory ratios, $\eta^{C A P}$ or $\eta^{L E V}$, and the tax rate away from their optimal levels and evaluate the impact on intermediaries' balance sheets, on risk taking and welfare.

We solve the model numerically using Carroll (2006)'s endogenous grid method with occasionally binding nonlinear constraints due to the limited liability of intermediaries and the possibility of a constrained interbank market or binding financial regulation constraints.

\subsubsection{Implementing the Social Optimum with Capital or Leverage Regulation}

We construct prices, asset returns and policy tools that implement the social optimum as a competitive equilibrium. First, the social optimum is implemented with interest rate policy, capital regulation and profit taxes, $\left(\frac{1}{p}, \eta^{C A P}, \tau\right)$. We refer to this implementation as the optimal CAP experiment. Alternatively, the optimal LEV experiment implements the social optimum with interest rate policy, leverage regulation and profit taxes, $\left(\frac{1}{p}, \eta^{L E V}, \tau\right)$.

Propositions 4 and 5 present some analytical results of these two implementations under specific assumptions regarding the bankruptcy of intermediaries. ${ }^{24}$ Subsequently, we use numerical simulations to confirm the bankruptcy patterns assumed in the propositions, and to discuss the key characteristics of the policy tools. The parameters used in our numerical

\footnotetext{
${ }^{24}$ For high productivity states, i.e. $s_{t}=\bar{s}$, it is possible to analytically derive all prices and asset returns that implement the social optimum as a competitive equilibrium. These details are not included in Proposition 4, but are available upon request from the authors.
} 
simulations are those from Tables 1 and 2, while the financial regulation bounds, $\eta^{C A P}$ or $\eta^{L E V}$, and the tax rate, $\tau$, are constructed to implement the social optimum.

Implementing the social optimum requires financial regulations to bind in expansions (Proposition 4), but not in recessions (Proposition 5). Moreover, there is a trade-off between the tax rate and the regulatory bounds that implement the social optimum (Proposition 4).

Proposition 4 Let the aggregate state at $t$ be $s_{t}=\bar{s}$. Assume that if $s_{t+1}=\underline{s}$, the highrisk intermediaries are bankrupt at $t+1$. Implementing the social optimum requires that $(i)$ financial regulations bind at $t$, and $(i i)$ the financial regulation bounds and the tax rate satisfy:

$$
\frac{1}{1-\tau\left(s^{t} \mid s_{t}=\bar{s}\right)}=Q_{1}^{i}\left(s^{t}\right)+Q_{2}^{i}\left(s^{t}\right) \frac{1}{\eta^{i}\left(s^{t} \mid s_{t}=\bar{s}\right)}, i \in\{C A P, L E V\}
$$

where the coefficients $Q_{1}^{i}\left(s^{t}\right), Q_{2}^{i}\left(s^{t}\right)$ for $i \in\{C A P, L E V\}$ are functions of the social planner's allocations and parameters $\beta, \delta, \theta, \alpha, \Phi, \pi_{j}, q_{j}(\bar{s})$ and $q_{j}(\underline{s})$ for $j \in\{h, l\}$.

Proof. See Appendix $A$.

Proposition 5 Let the aggregate state at $t$ be $s_{t}=\underline{s}$. Assume that no intermediary is bankrupt at $t+1$ for any realization of $s_{t+1} \in\{\bar{s}, \underline{s}\}$. Then, financial regulations do not bind at $t$ in implementations of the social optimum.

Proof. See Appendix $A$.

In what follows, we present results from the optimal CAP and optimal LEV experimentsthe two implementations we consider - for a sequence of 100 draws of the aggregate shock. We discuss further the features of the policy tools that implement the social optimum.

The net annualized interest rate policy, i.e., $100 \cdot\left[(1 / p)^{4}-1\right]$, is procylical (upper left subplot in Figure 2). During booms, interest rates in the optimal CAP experiment are 1.9 percentage points lower, on average, than in the optimal LEV experiment. During recessions, the interest rates in the two implementations are equal. The intuition for these results is the same as in the simple model of Section 3. The interbank market bond returns, $1 / \tilde{p}$, in the 
two experiments are equated with the expected return on investments in the social optimum. Under binding leverage regulation, the bond return, $1 / p$, is equal to $1 / \tilde{p}$. However, binding capital regulation during booms alters the composition of intermediaries' assets and lowers the bond return relative to the the interbank market bond return.

Unlike interest rate policy, the financial regulations and tax rates that implement the social optimum are not unique, as shown in Proposition 4. The state-dependent nature of the coefficients in equation (6) implies that either the profit tax rate, $\tau$, or the regulatory bounds, $\eta^{C A P}$ or $\eta^{L E V}$, must also depend on the model's state variables: household wealth, $w_{t}$, and aggregate productivity, $s_{t}$. In implementing the social optimum, we restrict the profit tax rate to vary only with aggregate productivity and let the regulatory bounds absorb any variation in wealth (i.e., compute $\eta^{C A P}\left(w_{t}, s_{t}=\bar{s}\right)$ or $\eta^{L E V}\left(w_{t}, s_{t}=\bar{s}\right)$ from (6)).

Specifically, we set $\tau(\bar{s})=0.0361$ to obtain an average minimum regulatory capital of 10.5 percent during high productivity periods, consistent with the Basel III regulation currently implemented in many countries (upper right subplot in Figure 2). We set the tax rate for the low productivity periods to $\tau(\underline{s})=0.0007$ to minimize the business cycle variation in the intermediaries' equity to risky capital ratio, i.e., $z / k$, in the implementation with capital regulation. We keep tax rates at the same level when implementing the social optimum with leverage regulation, and then back out $\eta^{L E V}\left(w_{t}, s_{t}=\bar{s}\right)$ from equation (6).

Figure 2 plots the minimum regulatory capital necessary to implement the social optimum and the actual equity to risky capital ratio in the optimal CAP experiment (lower left subplot), as well as the actual and the minimum required equity to deposit ratio in the optimal LEV experiment (lower right subplot). Note that our model calls for financial regulation constraints to be relaxed during recessions. Since financial regulations only bind in high productivity periods, we exogenously set the required regulatory ratios to zero in low productivity periods. ${ }^{25}$ Although we allow the regulatory bounds computed from equation (6) to vary with household wealth, the numerical results show that, during high productivity

\footnotetext{
${ }^{25}$ Alternatively, the required capital can be set to 8 percent or any lower number, as it would not bind.
} 
periods when wealth increases, $\eta^{C A P}\left(w_{t}, s_{t}=\bar{s}\right)$ and $\eta^{L E V}\left(w_{t}, s_{t}=\bar{s}\right)$ are flat. This result is desirable from a policymaker's perspective, since regulations that are independent of the model's endogenous state variable are easier to implement in practice.

Figure 3 compares simulation results from the optimal CAP and the optimal LEV experiments, for a sequence of 100 draws of the aggregate state. One important difference between the two implementations is that equity constitutes a larger fraction of total liabilities under optimal leverage regulation than under optimal capital regulation (upper right subplot). Since the fraction of assets invested in risky projects is the same across the two experiments (middle right subplot), the capital regulation constraint from the optimal CAP experiment is satisfied under the optimal LEV experiment. Thus, optimal leverage regulation imposes a stricter requirement on equity compared to optimal capital regulation, allowing the implementation of the social optimum without explicit restrictions on the composition of assets. A second difference between the optimal CAP and optimal LEV experiments is that the spread between the deposit rate and the government bond rate is positive in high productivity periods under optimal capital regulation, whereas it is always zero under optimal leverage regulation (lower right subplot). The positive spread is driven by differences in the bond rates across the two experiments; deposit rates are identical because they equal the expected return on investments in the social planner's problem (lower left subplot).

\subsubsection{Variations in the Optimal Policy Tools}

We conduct additional experiments to evaluate the impact of deviating from the optimal policies. We vary the interest rates, the financial regulatory bounds, and the tax rates that implement the social optimum and evaluate the impact on the balance sheet composition of intermediaries (Table 3), on asset returns, risk taking and welfare (Table 4). Balance sheet statistics and asset returns in our simulations are averages over simulations of 5,000 periods, while risk taking and welfare are averages over 5,000 simulations of 1,000 periods each.

We report results from several numerical experiments. The benchmark experiment is the 
economy calibrated as in Section 4.1, where the interest rate policy is chosen optimally, and $\eta^{C A P}=0.08, \eta^{L E V}=0, \tau=0$ in line with the Basel II capital regulation. The optimal CAP and the optimal LEV experiments are the two implementations of the social optimum discussed in Section 4.2.1. In addition, we conduct several experiments in which we change one policy tool at a time, while keeping the two other policy tools at their optimal levels. First, we keep $\eta^{C A P}$ and $\tau$ as in the optimal CAP experiment, but lower the interest rate schedule, $\frac{1}{p}$, by 1 percentage point at annual rates (experiment $2 a$ in Tables 3 and 4 ). Next, we keep $\frac{1}{p}$ and $\tau$ as in the optimal CAP experiment, but change the minimum regulatory capital, $\eta^{C A P}$, to 1 percent (experiment $2 b$ ) or 25 percent (experiment $2 c$ ). Lastly, we keep $\frac{1}{p}$ and $\eta^{C A P}$ as in the optimal CAP experiment, but set taxes, $\tau$, to zero (experiment $2 d$ ). Experiments $3 a, 3 b, 3 c$ and $3 d$ are defined analogously relative to the optimal LEV experiment. In experiments $3 b$ and $3 c, \eta^{L E V}$ is changed to 1 percent, or 20 percent, respectively.

Table 3 reports the intermediaries' balance sheet composition before and after interbank market repo trades. Compared with the benchmark - which is calibrated to match an average equity to asset ratio of 19 percent - the optimal CAP and optimal LEV experiments have lower equity to asset ratios, due to the incorporation of profit taxes in the optimal toolkit. Indeed, experiments $2 c$ and $3 c$ with zero taxes have equity to asset ratios comparable to those in the benchmark economy. Although the initial asset composition of intermediaries varies across experiments, once repo trades take place, high-risk intermediaries invest a fairly constant fraction of their balance sheet in risky assets, i.e., $k_{h} /(z+d)$ is on average 84 percent in all experiments. As a result, the total amount of resources allocated to high-risk investments, $k_{h}$, and risk taking relative to the social planner depend on the size of the balance sheet.

We investigate our numerical results further by examining the impact of changing one policy tool alone, i.e., either $\frac{1}{p}$, or $\eta^{C A P}$ or $\tau$, away from its optimal level in the optimal CAP experiment (i.e., experiment 2). Lowering the interest rate policy in experiment $2 a$ has a strong impact on the size of the balance sheet. To understand why, we write the balance 
sheet of the financial sector as $Z+D=Z+D_{h}+D_{g}=Z+D_{h}+p B$. Lower bond returns in experiment $2 a$ leave total equity and household deposits almost unchanged, but lead to a substantial reduction in bond purchases relative to experiment 2. Indeed, Table 3 shows that total equity is $0.078 \cdot 2.435=0.19$ in experiment 2 and $0.096 \cdot 0.804 \cdot 2.435=0.188$ in experiment $2 a$. Household deposits (not shown in the table) change from 1.65 in experiment 2 to 1.63 in experiment $2 a$. Lastly, bond purchases are $p B \simeq 0.243 * 2.435=0.59$ in experiment 2 and $p B \simeq 0.07 \cdot 0.804 \cdot 2.435=0.14$ in experiment $2 a$. Fewer bond purchases reduce the size of the balance sheet and the total amount of resources allocated to high-risk investments, $k_{h}$. As a result, risk taking in experiment $2 a$ is 19 percent lower relative to the social optimum (Table 4), whereas resources are allocated optimally in experiment 2.

Lowering the minimum regulatory capital to 1 percent in experiment $2 b$ allows intermediaries to hold less equity. Given more deposits, the moral hazard of intermediaries is more pronounced and risk taking is about 1.8 percent higher relative to the social optimum (Tables 3 and 4). Similarly, raising the minimum regulatory capital to 25 percent in experiment $2 c$ causes welfare losses since risk taking is lower relative to the social optimum. Lastly, eliminating the profit tax in experiment $2 d$ raises the returns on equity and the amount of equity on intermediaries' balance sheet. Risk taking, welfare and the balance sheet composition of intermediaries are similar to those in the benchmark model (see Tables 3 and 4).

Next, we use our numerical experiments to identify similarities and differences between capital and leverage regulations. We see that lowering the interest rate policy has similar effects on the balance sheet composition of intermediaries, on risk taking and on welfare, regardless of which regulation is in place (see experiments $2 a$ and $3 a$ in Tables 3 and 4). The remaining experiments establish two differences between capital and leverage regulation.

A first difference between the financial policy tools is that changes in leverage regulation away from its optimal level have stronger effects on risk taking and welfare than do changes in capital regulation. To establish this result, we compare experiment $2 b$ to $3 b$, and experiment $2 c$ to $3 c$. In experiments $2 b$ and $3 b$, we choose $\eta^{C A P}$ and $\eta^{L E V}$ so that equity represents 
about 2 percent of the intermediaries' balance sheet. In experiments $2 c$ and $3 c$, we choose $\eta^{C A P}$ and $\eta^{L E V}$ so that equity represents about 15 percent of intermediaries' balance sheet. In each pair of experiments, it is important to keep the equity share comparable, since equity directly affects the moral hazard of intermediaries. Table 4 shows that bond returns under leverage regulation are higher than under capital regulation. In experiment $3 b$, the higher bond returns lead intermediaries to purchase more bonds, expand their balance sheet and increase risk taking relative to experiment $2 b$. The intuition is similar to experiment 2a. However, in experiment $3 c$, despite higher bond returns intermediaries purchase fewer bonds than in experiment $2 c$. The reason is that government seigniorage from bond issuance, $R^{d} D_{g}-B=\left(R^{d}-1 / p\right) p B$, is negative in experiment $3 c$. Bond purchases, the balance sheet of intermediaries and risk taking are all lower in experiment $3 c$ than in $2 c$.

A second difference between the financial policy tools is that lowering taxes to zero has stronger effects on risk taking and welfare in the presence of leverage regulation (experiment $3 d$ ) than in the presence of capital regulation (experiment $2 d$ ). The intuition is comparable to that of experiments $2 b$ and $3 b$. Namely, under leverage regulation (experiment $3 d$ ), bond returns are higher and intermediaries buy more bonds, have larger balance sheets and engage in more risk taking than under capital regulation (experiment $2 d$ ).

To show that the results in Tables 3 and 4 hold more generally, we consider a wide range of variations in $\frac{1}{p}, \eta^{C A P}$ and $\eta^{L E V}$ relative to their levels in the optimal CAP or optimal LEV experiments. Figure 4 reports welfare and risk taking relative to the social planner for deviations in the optimal interest rate policy ranging from -2 to +2 percentage points at annual rates, while financial regulation bounds and taxes are maintained at their optimal CAP or optimal LEV levels. Moreover, Figure 4 reports results from experiments where the value of the capital regulation bound, $\eta^{C A P}$, varies from 1 percent to 99 percent, while interest rate policy and taxes are maintained at their optimal CAP levels. Similarly, we perform experiments where $\eta^{L E V}$ varies from 1 percent to 25 percent, which corresponds to an increase in intermediaries' deposit to equity ratio (i.e., leverage) between 4 and 100 . 
The left subplots in Figure 4 show that deviations in interest rate policy have similar effects on welfare and risk taking in the presence of capital or leverage regulation. Differences exist for large declines in interest rates. Namely, under leverage regulation if bond rates are reduced by more than 120 basis points below the optimal level, the interbank market shuts down in good times, limiting the reallocation of resources. Market shutdowns under capital regulation occur if bond rates are reduced by 180 basis points below the optimal level.

The middle plots in Figure 4 show that small variations in $\eta^{C A P}$ around its Basel III level of 10.5 percent have a small impact on risk taking and welfare. However, consistent with previous literature, large increases in $\eta^{C A P}$ are very costly (Van den Heuvel (2009)). The right plots in Figure 4 show that changing the leverage regulation has a bigger impact on risk taking than changing the capital regulation, while the magnitude of welfare losses is comparable to the deviations in interest rates. As expected, looser leverage constraints (e.g. $\eta^{L E V}$ around 1 percent, or leverage around 100) increase intermediaries' risk taking.

We conclude that changing one policy tool at a time away from its optimal level affects the bond return, $\frac{1}{p}$, government seigniorage, $\left(R^{d}-1 / p\right) p B$, and the size of intermediaries' balance sheet. Since intermediaries invest a fairly constant fraction of their balance sheet in risky projects, the size of the balance sheet ultimately determines risk taking and welfare relative to the social planner.

\section{Conclusion}

In this paper, we develop a model in which financial intermediaries' risky investments (i.e., risk taking) over the business cycle may exceed the social optimum owing to limited liability and deposit insurance. Our main contribution is to characterize the optimal policy tools that achieve efficient risk taking when the model is calibrated to the U.S. economy.

We show that the social optimum can be implemented in our calibrated economy with (i) interest rate policy, capital regulation and profit taxes, or with (ii) interest rate policy, 
leverage regulation and profit taxes. In either case, the optimal policy tools need to be coordinated, for several reasons. First, interest rate policy has a direct influence on the risk taking of intermediaries. Second, optimal interest rate policy alone cannot eliminate intermediaries's excessive risk taking. Third, there is a trade-off between profit taxes and the financial regulatory bounds. Lower taxes require tighter financial regulation constraints.

We find several interesting results regarding the optimal policy tools. First, all policy tools are countercyclical. Interest rates are higher during expansions; capital and leverage regulations bind in expansion periods and are relaxed during contractions; taxes are higher during expansions when moral hazard is elevated and intermediaries have incentives to engage in excessive risk taking. Second, bond rates are higher in the implementation with leverage regulation because capital regulation distorts the equilibrium bond return, as it directly affects the asset composition of intermediaries. Third, optimal leverage regulation imposes a stricter requirement on equity than the optimal capital regulation, allowing the implementation of the social optimum without explicit restrictions on the composition of assets of financial intermediaries.

We conduct additional experiments to evaluate the impact of deviating from the optimal policies. We find that lowering the interest rate policy has a big impact on risk taking in both of the implementations of the social optimum. Lower bond returns reduce bond purchases, the size of the balance sheet and the total amount of resources allocated to high-risk investments. Thus, risk taking and welfare are lower than optimal. Another important result is that variations in the capital requirement in the range contemplated by policymakers have a small impact on risk taking in the economy. However, variations in leverage regulation have a stronger impact on risk taking relative to comparable experiments with capital regulation, since bond returns are higher under leverage regulation. We conclude that leverage regulation is a promising alternative for controlling excessive risk taking of intermediaries, since it is easier to implement than capital regulation, which requires assessing the riskiness of all assets on an intermediary's balance sheet. 


\section{References}

Acharya, V. V., S. T. Bharath, and A. Srinivasan (2003): "Understanding the Recovery Rates on Defaulted Securities," CEPR Discussion Papers 4098.

Acharya, V. V., and P. Schnabl (2009): "How Banks Played the Leverage Game," in Restoring Financial Stability: How to Repair a Failed System, ed. by V. V. Acharya, and M. Richardson. John Wiley and Sons, Inc.

Adrian, T., ANd H. S. Shin (2010): "Liquidity and Leverage," Journal of Financial Intermediation, 19, 418-437.

Allen, F., And D. Gale (2000): "Bubbles and Crises," The Economic Journal, 110, 236255.

Altunbas, Y., L. Gambacorta, and D. Marques-Ibane (2014): "Does Monetary Policy Affect Risk Taking?," International Journal of Central Banking, 10(1), 95-135.

Angeloni, I., And E. FAia (2013): "Capital regulation and monetary policy with fragile banks," The Journal of Monetary Economics, 60, 311-324.

Basel Committee on Banking Supervision (2011): "Basel III: A Global Regulatory Framework for More Resilient Banks and Banking Systems," Bank for International Settlements.

Bernanke, B. S. (2010): "Monetary Policy and the Housing Bubble," speech at the Annual Meeting of the American Economic Association, Atlanta, Georgia, January 3.

Bernanke, B. S., And M. Gertler (1989): "Agency Costs, Net Worth and Business Fluctuations," American Economic Review, 79, 14-31.

Blanchard, O., G. Dell'Ariccia, and P. Mauro (2010): "Rethinking Macroeconomic Policy," Journal of Money, Credit and Banking, 42, 199-215.

Borio, C., And H. Zhu (2012): "Capital regulation, risk-taking and monetary policy: A missing link in the transmission mechanism?," Journal of Financial Stability, 8(4), 236251.

Carroll, C. D. (2006): "The Method of Endogenous Gridpoints for Solving Dynamic Stochastic Optimization Problems," Economics Letters, 91(3), 312-320.

Cecchetti, S. G., And M. Kohler (2012): "When Capital Adequacy and Interest Rate Policy are Substitutes (and when they are not)," BIS Working Paper 379.

Cerutti, E., S. Clafessens, and L. Laeven (2015): "The Use and Effectiveness of Macroprudential Policies: New Evidence," IMF working paper 15/61.

Christensen, I., C. Meh, And K. Moran (2011): "Bank Leverage Regulation and Macroeconomic Dynamics," Working Paper 11-32, Bank of Canada. 
Cociuba, S. E., M. Shukayev, and A. Ueberfeldt (2016): "Collateralized Borrowing and Risk Taking at Low Interest Rates," European Economic Review, 85, 62-83.

Collard, F., H. Dellas, B. Diba, and O. Loisel (2016): "Optimal Monetary and Prudential Policies," American Economic Journal: Macroeconomics, forthcoming.

Damar, E., And M. Molico (2016): "On the Nexus of Monetary Policy and Financial Stability: Effectiveness of Macroprudential Tools in Building Resilience and Mitigating Financial Imbalances," Bank of Canada Staff Discussion Paper 2016-11.

de Nicolò, G., G. Dell'Ariccia, L. Laeven, and F. Valencia (2010): "Monetary Policy and Bank Risk Taking," IMF Staff Position Note SPN/10/09.

Dell'Ariccia, G., L. Laeven, and R. Marquez (2014): "Real Interest Rates, leverage and bank risk-taking," Journal of Economic Theory, 149(1), 65-99.

Dubecq, S., B. Mojon, and X. Ragot (2015): "Risk Shifting with Fuzzy Capital Constraints," International Journal of Central Banking, 11(1), 71-101.

Eisfeldt, A. L., And A. A. RAmpini (2006): "Capital reallocation and liquidity," Journal of Monetary Economics, 53, 369-399.

Financial Stability Board (2012): "Securities Lending and Repos: Market Overview and Financial Stability Issues, Interim Report of the FSB Workstream on Securities Lending and Repos," April.

Gale, D. (2004): "Notes on Optimal Capital Regulation," in The Evolving Financial System and Public Policy, ed. by P. St-Amant, and C. Wilkins. Ottawa: Bank of Canada.

Gertler, M., and N. Kiyotaki (2010): "Financial Intermediation and Credit Policy in Business Cycle Analysis," Handbook of Monetary Economics, 3, 547-599.

Gorton, G., And A. Metrick (2012): "Securitized banking and the run on the repo," Journal of Financial Economics, 104(3), 425-451.

Hellwig, M. F. (2010): "Capital Regulation after the Crisis: Business as Usual?," CESifo DICE Report, 2/2010, pp. 40-46.

International Monetary Fund (2010): "A fair and substantial contribution by the financial sector," in Financial Sector Taxation: The IMF's Report to the G-20 and Background Material, ed. by S. Claessens, M. Keen, and C. Pazarbasioglu. International Monetary Fund.

Jeanne, O., And A. Korinek (2013): "Macroprudential Regulation versus Mopping Up after the Crash," NBER Working Paper 18675.

Keister, T. (2016): "Bailouts and Financial Fragility," Review of Economic Studies, 83, 704-736. 
Kelly, K., T. McGinty, and D. Fitzpatrick (2010): "Big Banks Mask Risk Levels," Wall Street Journal (Online), April 9.

Kiyotaki, N., and J. Moore (1997): "Credit Cycles," Journal of Political Economy, 105, 211-248.

Lim, C., F. Columba, A. Costa, P. Kongsamut, A. Otani, M. Saiyid, T. Wezel, AND X. WU (2011): "Macroprudential Policy: What Instruments and How to Use Them? Lessons from Country Experiences," IMF working paper 11/238.

Loisel, O. (2014): "Discussion of "Monetary and Macroprudential Policy in an Estimated DSGE Model of the Euro Area"," International Journal of Central Banking, 10, 237-248.

Macklem, T. (2011): "Mitigating Systemic Risk and the Role of Central Banks," speech at Conférence de Montréal, Montréal, Quebec, June 6.

Merton, R. C. (1973): "An Intertemporal Capital Asset Pricing Model," Econometrica, $41,867-887$.

Pennacchi, G. (2006): "Deposit Insurance, Bank Regulation, and Financial System Risks," Journal of Monetary Economics, 53, 1-30.

Ramey, V. A., and M. D. Shapiro (2001): "Displaced Capital: A Study of Aerospace Plant Closings," Journal of Political Economy, 109, 958-992.

Svensson, L. E. O. (2015): "Monetary Policy and Macroprudential Policy: Different and Separate," working paper, Stochholm School of Economics.

Van Den Heuvel, S. J. (2009): "The Welfare Cost of Bank Capital Requirements," Journal of Monetary Economics, 55, 298-320.

Yellen, J. L. (2010): "Macroprudential Supervision and Monetary Policy in the Post-crisis World," speech at the Annual Meeting of the National Association for Business Economics, Denver, Colorado, October 11. 


\section{A Appendix: Proofs of Propositions}

To simplify notation in our derivations, we use subscript $t-1$ as short-hand notation for dependence on history $s^{t-1}$. For example, we define $d_{t-1} \equiv d\left(s^{t-1}\right)$ and $\tilde{b}_{j, t-1} \equiv \tilde{b}_{j}\left(s^{t-1}\right)$. Moreover, we define $q_{j, t} \equiv q_{j}\left(s_{t}\right)$ but note that productivity depends only on the current realization of the aggregate shock.

\section{Proof of Proposition 1.}

In an interior competitive equilibrium, expected returns on deposits are positive and equal to the expected returns on financial equity (i.e., expected profits per unit of equity).

$$
R_{t-1}^{d} \sum_{s^{t} \mid s^{t-1}} \lambda_{t}=\sum_{s^{t} \mid s^{t-1}} \lambda_{t} R_{t}^{z}=\sum_{s^{t} \mid s^{t-1}} \lambda_{t} \frac{1-\tau_{t-1}}{z_{t-1}}\left[\pi_{h} V_{h, t}+\pi_{l} V_{l, t}\right]>0
$$

Thus, some intermediary $j$ makes strictly positive profits for some aggregate state $s_{t}$.

Using the result that wage rates equal the marginal product of labor and that $l_{j, t}=1$ in equilibrium, equation $(2)$ can be written as in equation $(A .1)$, where notice that all variables except for $q_{j, t}$ depend on the shock from $t-1$.

$$
V_{j, t}=\max \left\{\left[\begin{array}{l}
(\theta+\alpha) q_{j, t}\left(k_{t-1}+\tilde{p}_{t-1} \tilde{b}_{j, t-1}\right)^{\theta}+q_{j, t}(1-\delta)\left(k_{t-1}+\tilde{p}_{t-1} \tilde{b}_{j, t-1}\right) \\
+b_{t-1}-\tilde{b}_{j, t-1}-R_{t-1}^{d} d_{t-1}
\end{array}\right], 0\right\}
$$

The ranking of productivity levels and equation (A.1) imply that profits in a good state are at least as big as profits in a bad state: $V_{h, t}(\bar{s})>V_{h, t}(\underline{s})$ and $V_{l, t}(\bar{s})=V_{l, t}(\underline{s})$. Let $I_{j, t}$ be an indicator function that equals 1 if intermediary $j$ 's gross profit, i.e., the term in the square bracket in equation $(A .1)$, is positive. Then, either $I_{h, t}(\bar{s})=1$ or $I_{l, t}(\bar{s})=1$ or both. If low-risk intermediaries default in both states, there are no trades in the interbank market. We rule out this uninteresting case. It follows that, at least in the good aggregate state, there is no default: $I_{h, t}(\bar{s})=I_{l, t}(\bar{s})=1$. Since $V_{l, t}(\bar{s})=V_{l, t}(\underline{s})$, the low-risk intermediary does not default in the bad state, $I_{h, t}(\bar{s})=I_{l, t}(\bar{s})=I_{l, t}(\underline{s})=1$ for all $t$. Lastly, in a bad aggregate state, high-risk intermediaries may either default, or not, $I_{h, t}(\underline{s}) \in\{0,1\}$.

\section{Proof of Proposition 2.}

(i) Let superscript SP index variables that pertain to the social planner's problem. If the competitive equilibrium allocation coincides with the social optimum then: $C_{t}=C_{t}^{S P}$, $k_{j, t-1}=k_{t-1}+\tilde{p}_{t-1} \tilde{b}_{j, t-1}=k_{j, t-1}^{S P}$ for $j \in\{h, l\}$, and $k_{m, t-1}=k_{m, t-1}^{S P}$. Comparing first order conditions in the two environments, we find $\lambda_{t}=\lambda_{t}^{S P}$, as well as equation (A.2).

$$
\begin{aligned}
\lambda_{t-1} & =\beta R_{t-1}^{d} \sum_{s^{t} \mid s^{t-1}} \lambda_{t}=\beta \sum_{s^{t} \mid s^{t-1}} \lambda_{t}^{S P} q_{j, t} \theta\left(k_{j, t-1}\right)^{\theta-1}=\lambda_{t-1}^{S P} \text { for } j \in\{h, l\} \\
0 & =\sum_{s^{t} \mid s^{t-1}} \lambda_{t}^{S P}\left[q_{j, t} \theta\left(k_{j, t-1}^{S P}\right)^{\theta-1}-R_{t-1}^{d}\right] \text { for } j \in\{h, l\}
\end{aligned}
$$


Dividing by $\lambda_{t-1}^{S P}$ and using $\frac{\lambda_{t}^{S P}}{\lambda_{t-1}^{S P}}=\frac{\lambda_{t}}{\lambda_{t-1}}=\varphi\left(s^{t} \mid s^{t-1}\right)=\varphi\left(s_{t}\right)$, equation $(A .2)$ becomes:

$$
0=\sum_{s^{t} \mid s^{t-1}} \varphi\left(s_{t}\right)\left[q_{j, t} \theta\left(k_{j, t-1}^{S P}\right)^{\theta-1}-R_{t-1}^{d}\right] \text { for } j \in\{h, l\}
$$

Using $\lambda_{t}=\lambda_{t}^{S P}, k_{j, t-1}=k_{j, t-1}^{S P}$ and the assumption that there is no bankruptcy in the competitive equilibrium, i.e., $I_{j}\left(s_{t}\right)=1$ for all $j$ and for all $s_{t}$, an intermediary's first order condition with respect to $d_{t-1}$ becomes:

$$
\left(1-\tau_{t-1}\right) \cdot \sum_{j \in\{h, l\}} \pi_{j} \sum_{s^{t} \mid s^{t-1}} \lambda_{t}^{S P}\left[q_{j, t} \theta\left(k_{j, t-1}^{S P}\right)^{\theta-1}-R_{t-1}^{d}\right]=\zeta_{t-1}^{C A P} \eta_{t-1}^{C A P}+\zeta_{t-1}^{L E V} \eta_{t-1}^{L E V}
$$

Comparing $(A .2)$ and (A.4), it follows that an equilibrium implements the planner's allocation if $\zeta_{t-1}^{C A P} \eta_{t-1}^{C A P}+\zeta_{t-1}^{L E V} \eta_{t-1}^{L E V}=0$. Since $\zeta_{t-1}^{C A P} \geq 0, \eta_{t-1}^{C A P} \geq 0, \zeta_{t-1}^{L E V} \geq 0$ and $\eta_{t-1}^{L E V} \geq 0$, it follows that either the capital and leverage regulations are absent $\left(\eta_{t-1}^{C A P}=\eta_{t-1}^{L E V}=0\right)$ or they do not bind $\left(\zeta_{t-1}^{C A P}=\zeta_{t-1}^{L E V}=0\right)$.

(ii) First, we show that in a competitive equilibrium in which capital regulation does not bind, the bond returns on the primary and the interbank market are equal, i.e., $\frac{1}{p_{t-1}}=\frac{1}{\tilde{p}_{t-1}}$.

The first order condition with respect to $b_{t-1}$ is:

$$
\left(1-\tau_{t-1}\right)\left(1-\frac{\tilde{p}_{t-1}}{p_{t-1}}\right) \cdot \Xi_{t}-\zeta_{t-1}^{C A P} \eta_{t-1}^{C A P}=0
$$

where $\Xi_{t} \equiv \sum_{j \in\{h, l\}} \pi_{j} \sum_{s^{t} \mid s^{t-1}} \frac{\lambda_{t}}{\lambda_{t-1}} I_{j, t} q_{j, t} \theta\left(z_{t-1}+d_{t-1}-p_{t-1} b_{t-1}+\tilde{p}_{t-1} \tilde{b}_{j, t-1}\right)^{\theta-1}$. Note that $\Xi_{t}>0$, because not all intermediaries are bankrupt in equilibrium. Moreover, $\tau_{t-1} \in$ $[0,1)$. As a result, in the absence of capital regulation $\left(\eta_{t-1}^{C A P}=0\right)$, or if this regulation does not bind $\left(\zeta_{t-1}^{C A P}=0\right)$, the primary and interbank market bond prices are equated, $p_{t-1}=\tilde{p}_{t-1}$. In particular, since $\eta_{t-1}^{L E V}$ does not enter equation $(A .5)$, leverage regulation doesn't drive a wedge between $p_{t-1}$ and $\tilde{p}_{t-1}$.

Next, we show that to implement the social optimum as a competitive equilibrium, the return on deposits and the interbank market bond return must satisfy, $R_{t-1}^{d}=\frac{1}{\tilde{p}_{t-1}}$.

The assumption that high-risk intermediaries have higher expected productivity (see assumption $A 1(v)$ ) means that low-risk intermediaries purchase bonds on the interbank market. Thus, $\tilde{b}_{l, t-1}<0<b_{t-1}$ and the complimentary slackness conditions imply that the collateral constraint does not bind for low-risk intermediaries, $\mu_{l, t-1}=0$. Then, the first order condition with respect to $\tilde{b}_{l, t-1}$ becomes:

$$
\frac{1-\tau_{t-1}}{\lambda_{t}^{S P}} \sum_{s^{t} \mid s^{t-1}} \lambda_{t}^{S P}\left[q_{l, t} \theta\left(k_{l, t-1}^{S P}\right)^{\theta-1}-\frac{1}{\tilde{p}_{t-1}}\right]=0
$$

where we have used $\lambda_{t}=\lambda_{t}^{S P}, k_{l, t}=k_{l, t}^{S P}$ and $I_{l, t} \equiv I_{l}\left(s_{t}\right)=1$ for all $s_{t}$.

Combining $(A .2)$ and $(A .6)$ gives $R_{t-1}^{d}=\frac{1}{\tilde{p}_{t-1}}$. We have shown that $R_{t-1}^{d}=\frac{1}{\tilde{p}_{t-1}}=\frac{1}{p_{t-1}}$. Under assumptions $A 1$, the households' first order conditions give $R_{t-1}^{d}=\frac{1}{\beta}$. Thus, $\frac{1}{p_{t-1}}=\frac{1}{\beta}$. 
(iii) In an interior competitive equilibrium, expected returns on deposits are equal to the expected returns on financial equity (i.e., expected profits per unit of equity).

$$
\begin{aligned}
& R_{t-1}^{d} \sum_{s^{t} \mid s^{t-1}} \lambda_{t}=\sum_{s^{t} \mid s^{t-1}} \lambda_{t} \frac{1-\tau_{t-1}}{z_{t-1}}\left[\pi_{h} V_{h, t}+\pi_{l} V_{l, t}\right] \\
& R_{t-1}^{d} \sum_{s^{t} \mid s^{t-1}} \lambda_{t}=\sum_{s^{t} \mid s^{t-1}} \lambda_{t} \frac{1-\tau_{t-1}}{z_{t-1}}\left[\pi_{h} \theta q_{h, t} k_{h, t-1}^{\theta}+\pi_{l} \theta q_{l, t} k_{l, t-1}^{\theta}+b_{t-1}-R_{t-1}^{d} d_{t-1}\right]
\end{aligned}
$$

To obtain the last equation, we used the definition of $V_{j, t}$, the fact that $\pi_{h}+\pi_{l}=1$, as well as the market clearing condition $\pi_{h} \tilde{b}_{h, t-1}+\pi_{l} \tilde{b}_{l, t-1}=0$. Rearranging terms, we find:

$$
\left(\frac{z_{t-1}}{1-\tau_{t-1}}+d_{t-1}\right) R_{t-1}^{d} \sum_{s^{t} \mid s^{t-1}} \lambda_{t}=\sum_{s^{t} \mid s^{t-1}} \lambda_{t}\left(\sum_{j \in\{h, l\}} \pi_{j} \theta q_{j, t} k_{j, t-1}^{\theta}\right)+b_{t-1} \sum_{s^{t} \mid s^{t-1}} \lambda_{t}
$$

Next, use equation $(A .2)$, that is: $R_{t-1}^{d} \sum_{s^{t} \mid s^{t-1}} \lambda_{t}=\sum_{s^{t} \mid s^{t-1}} \lambda_{t} \theta q_{j, t} k_{j, t-1}^{\theta-1}$, to write:

$$
\left(\pi_{h} k_{h, t-1}+\pi_{l} k_{l, t-1}\right) R_{t-1}^{d} \sum_{s^{t} \mid s^{t-1}} \lambda_{t}=\pi_{h} \sum_{s^{t} \mid s^{t-1}} \lambda_{t} \theta q_{h, t} k_{h, t-1}^{\theta}+\pi_{l} \sum_{s^{t} \mid s^{t-1}} \lambda_{t} \theta q_{l, t} k_{l, t-1}^{\theta}
$$

Thus, we find:

$$
\begin{aligned}
\left(\frac{z_{t-1}}{1-\tau_{t-1}}+d_{t-1}\right) R_{t-1}^{d} \sum_{s^{t} \mid s^{t-1}} \lambda_{t} & =\left(\pi_{h} k_{h, t-1}+\pi_{l} k_{l, t-1}\right) R_{t-1}^{d} \sum_{s^{t} \mid s^{t-1}} \lambda_{t}+b_{t-1} \sum_{s^{t} \mid s^{t-1}} \lambda_{t} \\
\frac{z_{t-1}}{1-\tau_{t-1}}+d_{t-1} & =\pi_{h} k_{h, t-1}+\pi_{l} k_{l, t-1}+\frac{1}{R_{t-1}^{d}} b_{t-1}
\end{aligned}
$$

As shown in $(i i)$, to implement the social optimum as a competitive equilibrium, it must be that $R_{t-1}^{d}=\frac{1}{\tilde{p}_{t-1}}$. Moreover, as shown in $(i i)$, when capital and leverage regulations do not bind, bond prices satisfy $\frac{1}{\tilde{p}_{t-1}}=\frac{1}{p_{t-1}}$. Thus, we get $\frac{z_{t-1}}{1-\tau_{t-1}}+d_{t-1}=\pi_{h} k_{h, t-1}+\pi_{l} k_{l, t-1}+p_{t-1} b_{t-1}$.

Moreover, $\pi_{h} k_{h, t-1}+\pi_{l} k_{l, t-1}=k_{t-1}$. Aggregating $k_{t-1}+p_{t-1} b_{t-1}=z_{t-1}+d_{t-1}$ yields $\left(1-\pi_{m}\right) k_{t-1}+p_{t-1} B_{t-1}=Z_{t-1}+D_{h, t-1}+D_{g, t-1}$, or $\left(1-\pi_{m}\right) k_{t-1}=Z_{t-1}+D_{h, t-1}$ and so:

$$
\frac{z_{t-1}}{1-\tau_{t-1}}+d_{t-1}=k_{t-1}+p_{t-1} b_{t-1}=\frac{Z_{t-1}+D_{h, t-1}}{1-\pi_{m}}+\frac{p_{t-1} B_{t-1}}{1-\pi_{m}}=\frac{Z_{t-1}+D_{h, t-1}+D_{g, t-1}}{1-\pi_{m}}=z_{t-1}+d_{t-1}
$$

Thus, $\tau_{t-1}=0$.

(iv) It is sufficient to derive conditions under which high-risk intermediaries do not go bankrupt in the event of a bad aggregate state. Then, as argued in Proposition 1, no intermediary goes bankrupt, i.e., $I_{j}\left(s_{t}\right)=1$ for all $j \in\{h, l\}$ and for all $s_{t} \in\{\bar{s}, \underline{s}\}$.

Using equation (2), the condition $V_{h, t} \geq 0$ is equivalent to $\theta q_{h, t} k_{h, t-1}^{\theta}+b_{t-1}-\frac{1}{\tilde{p}_{t-1}}\left(k_{h, t-1}-\right.$ $\left.k_{t-1}\right)-R_{t-1}^{d} d_{t-1} \geq 0$, where we have used the fact that $k_{h, t-1}=k_{t-1}+\tilde{p}_{t-1} \tilde{b}_{h, t-1}$. Let $x_{t-1}$ be the fraction of resources an intermediary retains for risky investments in the primary market portfolio decision. Namely, $k_{t-1}=x_{t-1}\left(z_{t-1}+d_{t-1}\right)$ and $p_{t-1} b_{t-1}=\left(1-x_{t-1}\right)\left(z_{t-1}+d_{t-1}\right)$. The no default condition for high-risk intermediaries is:

$$
\theta q_{h, t} k_{h, t-1}^{\theta}-\frac{1}{\tilde{p}_{t-1}} k_{h, t-1}+\frac{1}{p_{t-1}}\left(1-x_{t-1}\right)\left(z_{t-1}+d_{t-1}\right)+\frac{1}{\tilde{p}_{t-1}} x_{t-1}\left(z_{t-1}+d_{t-1}\right)-R_{t-1}^{d} d_{t-1} \geq 0
$$


As shown in Proposition 2, if a competitive equilibrium with no bankruptcy implements the social optimum, then $\tilde{b}_{j, t-1}<b_{t-1}$, and $\mu_{j, t-1}=0$. Moreover, since $R_{t-1}^{d}=\frac{1}{p_{t-1}}=\frac{1}{\tilde{p}_{t-1}}$, equation (A.7) becomes: $\theta q_{h, t} k_{h, t-1}^{\theta}+R_{t-1}^{d}\left(z_{t-1}-k_{h, t-1}\right) \geq 0$.

The level of equity at which the high-risk intermediary doesn't go bankrupt is:

$$
\begin{aligned}
& z_{t-1} \geq k_{h, t-1}-\frac{1}{R_{t-1}^{d}} \theta q_{h, t} k_{h, t-1}^{\theta} \\
& z_{t-1} \geq k_{h, t-1}\left[1-\tilde{p}_{t-1} \theta q_{h, t} k_{h, t-1}^{\theta-1}\right]
\end{aligned}
$$

Assuming no bankruptcy, $I_{j}\left(s_{t}\right)=1$ for all $j$ and for all $s_{t}$, and using the result that $\mu_{j, t-1}=0$, the first order condition with respect to $\tilde{b}_{j, t-1}$ can be written as:

$$
k_{j, t-1} \equiv k_{t-1}+\tilde{p}_{t-1} \tilde{b}_{j, t-1}=\left[\frac{1}{\tilde{p}_{t-1} \theta} \cdot \frac{\sum_{s^{t} \mid s^{t-1}} \frac{\lambda_{t}}{\lambda_{t-1}}}{\sum_{s^{t} \mid s^{t-1}} \frac{\lambda_{t}}{\lambda_{t-1}} q_{j, t}}\right]^{\frac{1}{\theta-1}}=\left[\frac{1}{\tilde{p}_{t-1} \theta} \cdot \frac{1}{\phi q_{j}(\bar{s})+(1-\phi) q_{j}(\underline{s})}\right]^{\frac{1}{\theta-1}}
$$

where we have used $\frac{\lambda_{t}}{\lambda_{t-1}}=\varphi\left(s^{t} \mid s^{t-1}\right)=\varphi\left(s_{t}\right)$ and $\sum_{s^{t} \mid s^{t-1}} \varphi\left(s_{t}\right)=1$.

Equation (A.8) becomes:

$$
z_{t-1} \geq k_{h, t-1}\left[1-\frac{q_{h}\left(s_{t}\right)}{\phi q_{h}(\bar{s})+(1-\phi) q_{h}(\underline{s})}\right] \text { for all } s_{t} \in\{\bar{s}, \underline{s}\}
$$

Using $q_{h}(\bar{s})>q_{h}(\underline{s})$, the inequality in $(A .9)$ becomes: $\frac{z_{t-1}}{k_{h, t-1}} \geq 1-\frac{1}{\phi \frac{q_{h}(\bar{s})}{q_{h}(s)}+1-\phi}$.

Since high-risk intermediaries sell bonds on the interbank market, we have $k_{h, t-1}>k_{t-1}$ and thus $z_{t-1} / k_{t-1}>z_{t-1} / k_{h, t-1} \geq 1-\frac{1}{\phi \frac{q_{h}(\bar{s})}{q_{h}(\underline{s})}+1-\phi}$.

\section{Proof of Proposition 3.}

First, we show that either binding capital regulation or binding leverage regulation are necessary to implement the social optimum as a competitive equilibrium with bankruptcy of high-risk intermediaries. Let $I_{j, t}$ be an indicator function which equals 1 if intermediary $j$ 's gross profit at time $t$ (i.e., the term in the square bracket in equation $(A .1)$ ) is positive. Assume that for some $t, I_{h, t}(\underline{s})=0$ and $I_{h, t}(\bar{s})=I_{l, t}(\bar{s})=I_{l, t}(\underline{s})=1$. The first order condition with respect to deposits evaluated at the optimal allocation (i.e., using $\lambda_{t}=\lambda_{t}^{S P}$ and $\left.k_{j, t-1}=k_{j, t-1}^{S P}\right)$ and using $\frac{\lambda_{t}}{\lambda_{t-1}}=\varphi\left(s^{t} \mid s^{t-1}\right)=\varphi\left(s_{t}\right)$, becomes:

$$
\begin{aligned}
\zeta_{t-1}^{C A P} \eta_{t-1}^{C A P}+\zeta_{t-1}^{L E V} \eta_{t-1}^{L E V}= & \left(1-\tau_{t-1}\right) \pi_{h} \cdot \varphi(\bar{s})\left[q_{h}(\bar{s}) \theta\left(k_{h, t-1}^{S P}\right)^{\theta-1}-R_{t-1}^{d}\right] \\
& +\left(1-\tau_{t-1}\right) \pi_{l} \cdot \sum_{s^{t} s^{t-1}} \frac{\lambda_{t}^{S P}}{\lambda_{t-1}^{S P}}\left[q_{l, t} \theta\left(k_{l, t-1}^{S P}\right)^{\theta-1}-R_{t-1}^{d}\right] \\
\zeta_{t-1}^{C A P} \eta_{t-1}^{C A P}+\zeta_{t-1}^{L E V} \eta_{t-1}^{L E V}= & \left(1-\tau_{t-1}\right) \pi_{h} \cdot \phi\left[q_{h}(\bar{s}) \theta\left(k_{h, t-1}^{S P}\right)^{\theta-1}-R_{t-1}^{d}\right]
\end{aligned}
$$

where to obtain $(A .10)$ we used $(A .2)$ as well as $\varphi(\bar{s})=\phi$. 
Using (A.2) again for $j=h$, we can express $R^{d}$ as below.

$$
R_{t-1}^{d}=\frac{\sum_{s^{t} \mid s^{t-1}} \lambda_{t}^{S P} q_{h, t} \theta\left(k_{h, t-1}^{S P}\right)^{\theta-1}}{\sum_{s^{t} \mid s^{t-1}} \lambda_{t}^{S P}}=\frac{\sum_{s^{t} \mid s^{t-1}} \frac{\lambda_{t}^{S P}}{\lambda_{t-1}^{S P}} q_{h, t} \theta\left(k_{h, t-1}^{S P}\right)^{\theta-1}}{\sum_{s^{t} \mid s^{t-1}} \frac{\lambda_{t}^{S P}}{\lambda_{t-1}^{S P}}}=\sum_{s^{t} \mid s^{t-1}} \varphi\left(s_{t}\right) q_{h, t} \theta\left(k_{h, t-1}^{S P}\right)^{\theta-1}
$$

With this expression for $R_{t-1}^{d}$, equation $(A .10)$ simplifies further as shown below.

$$
\frac{\zeta_{t-1}^{C A P} \eta_{t-1}^{C A P}+\zeta_{t-1}^{L E V} \eta_{t-1}^{L E V}}{\left(1-\tau_{t-1}\right) \pi_{h} \cdot \phi}=(1-\phi) \theta\left(k_{h, t-1}^{S P}\right)^{\theta-1}\left[q_{h}(\bar{s})-q_{h}(\underline{s})\right]>0
$$

Thus, $\zeta_{t-1}^{C A P} \eta_{t-1}^{C A P}+\zeta_{t-1}^{L E V} \eta_{t-1}^{L E V}>0$, which means that to implement the social optimum in an equilibrium with bankruptcy, either the capital regulation binds $\left(\zeta_{t-1}^{C A P}>0\right)$ or the leverage regulation binds $\left(\zeta_{t-1}^{L E V}>0\right)$, or both.

Next, we show that interest rate policy $\frac{1}{p_{t-1}}<\frac{1}{\beta}$, binding capital regulation, i.e., $z_{t-1}=$ $\eta_{t-1}^{C A P} k_{t-1}$, and a profit tax, $\tau_{t-1} \geq 0$, implement the social optimum as a competitive equilibrium with bankruptcy. Moreover, we show there is a trade-off between capital regulation and taxes, i.e., $\frac{\partial \eta_{t-1}^{C A P}}{\partial \tau_{t-1}}<0$. If tax rates are low, the minimum regulatory capital necessary to implement the social optimum is high.

If capital regulation binds, equation $(A .5)$ implies that $\frac{1}{p_{t-1}}<\frac{1}{\tilde{p}_{t-1}}$. Moreover, the proof of Proposition 2 shows that in order to implement the social optimum as a competitive equilibrium, we must have $R_{t-1}^{d}=\frac{1}{\tilde{p}_{t-1}}=\frac{1}{\beta}$. Thus, with binding capital regulation in place, the interest rate policy satisfies $\frac{1}{p_{t-1}}<\frac{1}{\beta}$.

In an interior equilibrium, expected returns on deposits and financial equity are equated.

$$
R_{t-1}^{d} \sum_{s^{t} \mid s^{t-1}} \lambda_{t}=\sum_{s^{t} \mid s^{t-1}} \lambda_{t} R_{t}^{z}=\sum_{s^{t} \mid s^{t-1}} \lambda_{t} \frac{1-\tau_{t-1}}{z_{t-1}}\left[\pi_{h} V_{h, t}+\pi_{l} V_{l, t}\right]>0
$$

Dividing both sides by $\lambda_{t-1}$, and using $\frac{\lambda_{t}}{\lambda_{t-1}}=\varphi\left(s^{t} \mid s^{t-1}\right)=\varphi\left(s_{t}\right)$ and $\sum_{s^{t} \mid s^{t-1}} \varphi\left(s_{t}\right)=1$, we find: $R_{t-1}^{d}=\sum_{s^{t} \mid s^{t-1}} \varphi\left(s_{t}\right) \frac{1-\tau_{t-1}}{z_{t-1}}\left[\pi_{h} V_{h, t}+\pi_{l} V_{l, t}\right]$.

Using $I_{h}(\underline{s})=0$ and $I_{h}(\bar{s})=I_{l}(\bar{s})=I_{l}(\underline{s})=1, \tilde{b}_{h, t-1}=b_{t-1}$ and $\tilde{b}_{l, t-1}=-\frac{\pi_{h}}{\pi_{l}} b_{t-1}$, and evaluating the expression at the optimal allocation (i.e., using $k_{j, t-1}=k_{j, t-1}^{S P}$ ), we find:

$$
\begin{aligned}
R_{t-1}^{d}= & \frac{1-\tau_{t-1}}{z_{t-1}} \cdot \varphi(\bar{s}) \pi_{h}\left[\theta q_{h}(\bar{s})\left(k_{h, t-1}^{S P}\right)^{\theta}-R_{t-1}^{d} d_{t-1}\right] \\
& +\frac{1-\tau_{t-1}}{z_{t-1}} \cdot \sum_{s^{t} \mid s^{t-1}} \varphi\left(s_{t}\right) \pi_{l}\left[\theta q_{l, t}\left(k_{l, t-1}^{S P}\right)^{\theta}+\frac{b_{t-1}}{\pi_{l}}-R_{t-1}^{d} d_{t-1}\right]
\end{aligned}
$$

As shown in the proof of Proposition 2, in order to implement the social optimum as a competitive equilibrium, we must have $R_{t-1}^{d}=\frac{1}{\tilde{p}_{t-1}}=\frac{1}{\beta}$. Then,

$$
b_{t-1}=\frac{k_{h, t-1}-k_{t-1}}{\tilde{p}_{t-1}}=\frac{k_{h, t-1}-\left(\pi_{h} k_{h, t-1}+\pi_{l} k_{l, t-1}\right)}{\tilde{p}_{t-1}}=R_{t-1}^{d} \pi_{l}\left(k_{h, t-1}^{S P}-k_{l, t-1}^{S P}\right)
$$


Using (A.2), and the equation above, (A.11) becomes:

$$
\begin{aligned}
\frac{z_{t-1}}{1-\tau_{t-1}} R_{t-1}^{d}= & \varphi(\bar{s}) \pi_{h}\left[\theta q_{h}(\bar{s})\left(k_{h, t-1}^{S P}\right)^{\theta}-R_{t-1}^{d} d_{t-1}\right]+k_{l, t-1}^{S P} \pi_{l} R_{t-1}^{d} \sum_{s^{t} \mid s^{t-1}} \varphi\left(s_{t}\right) \\
& +\pi_{l} R_{t-1}^{d}\left(k_{h, t-1}^{S P}-k_{l, t-1}^{S P}\right) \sum_{s^{t} \mid s^{t-1}} \varphi\left(s_{t}\right)-\pi_{l} R_{t-1}^{d} d_{t-1} \sum_{s^{t} \mid s^{t-1}} \varphi\left(s_{t}\right) \\
= & \varphi(\bar{s}) \pi_{h}\left[\theta q_{h}(\bar{s})\left(k_{h, t-1}^{S P}\right)^{\theta}-R_{t-1}^{d} d_{t-1}\right]+\pi_{l} R_{t-1}^{d}\left(k_{h, t-1}^{S P}-d_{t-1}\right)
\end{aligned}
$$

where we have used $\sum_{s^{t} \mid s^{t-1}} \varphi\left(s_{t}\right)=1$. Divide by $R_{t-1}^{d}=\frac{1}{\beta}$ and use $\varphi(\bar{s})=\phi$ to get:

$$
\begin{aligned}
\frac{z_{t-1}}{1-\tau_{t-1}} & =\phi \pi_{h}\left[\beta \theta q_{h}(\bar{s})\left(k_{h, t-1}^{S P}\right)^{\theta}-d_{t-1}\right]+\pi_{l}\left(k_{h, t-1}^{S P}-d_{t-1}\right) \\
\frac{z_{t-1}}{1-\tau_{t-1}} & =k_{h, t-1}^{S P}\left[\phi \pi_{h} q_{h}(\bar{s}) \beta \theta\left(k_{h, t-1}^{S P}\right)^{\theta-1}+\pi_{l}\right]-\left(\phi \pi_{h}+\pi_{l}\right) d_{t-1}
\end{aligned}
$$

Using $k_{h, t-1}^{1-\theta}=\beta \theta\left[\phi q_{h}(\bar{s})+(1-\phi) q_{h}(\underline{s})\right]$ we find

$$
\frac{z_{t-1}}{1-\tau_{t-1}}=k_{h, t-1}^{S P}\left[\phi \pi_{h} \frac{q_{h}(\bar{s})}{\phi q_{h}(\bar{s})+(1-\phi) q_{h}(\underline{s})}+\pi_{l}\right]-\left(\phi \pi_{h}+\pi_{l}\right) d_{t-1}
$$

Using $k_{h, t-1}^{S P}=z_{t-1}+d_{t-1}$ and $z_{t-1}=\eta_{t-1}^{C A P} k_{t-1}$, we find

$$
\begin{aligned}
\frac{\eta_{t-1}^{C A P} k_{t-1}}{1-\tau_{t-1}} & =k_{h, t-1}^{S P}\left[\phi \pi_{h} \frac{q_{h}(\bar{s})}{\phi q_{h}(\bar{s})+(1-\phi) q_{h}(\underline{s})}+\pi_{l}\right]-\left(\phi \pi_{h}+\pi_{l}\right)\left(k_{h, t-1}^{S P}-\eta_{t-1}^{C A P} k_{t-1}\right) \\
& =k_{h, t-1}^{S P}\left[\phi \pi_{h} \frac{q_{h}(\bar{s})}{\phi q_{h}(\bar{s})+(1-\phi) q_{h}(\underline{s})}-\phi \pi_{h}\right]+\left(\phi \pi_{h}+\pi_{l}\right) \eta_{t-1}^{C A P} k_{t-1} \\
& =\phi \pi_{h} k_{h, t-1}^{S P} \cdot \frac{(1-\phi)\left[q_{h}(\bar{s})-q_{h}(\underline{s})\right]}{\phi q_{h}(\bar{s})+(1-\phi) q_{h}(\underline{s})}+\left(\phi \pi_{h}+\pi_{l}\right) \eta_{t-1}^{C A P} k_{t-1}
\end{aligned}
$$

Simplifying, we find

$$
\frac{1}{1-\tau_{t-1}}=\pi_{l}+\phi \pi_{h}+\frac{\pi_{h} k_{h, t-1}^{S P}}{k_{t-1}} \cdot \frac{\phi(1-\phi)\left[q_{h}(\bar{s})-q_{h}(\underline{s})\right]}{\phi q_{h}(\bar{s})+(1-\phi) q_{h}(\underline{s})} \frac{1}{\eta_{t-1}^{C A P}}
$$

Using $k_{j, t-1}^{1-\theta}=\beta \theta\left[\phi q_{j}(\bar{s})+(1-\phi) q_{j}(\underline{s})\right]$ and also $k_{t-1}=\pi_{h} k_{h, t-1}+\pi_{l} k_{l, t-1}$ we find

$$
\frac{1}{1-\tau_{t-1}}=\pi_{l}+\phi \pi_{h}+\frac{\phi(1-\phi)\left[q_{h}(\bar{s})-q_{h}(\underline{s})\right]}{\phi q_{h}(\bar{s})+(1-\phi) q_{h}(\underline{s})} \cdot \frac{\pi_{h}\left[\phi q_{h}(\bar{s})+(1-\phi) q_{h}(\underline{s})\right]^{\frac{1}{1-\theta}}}{\sum_{j} \pi_{j}\left[\phi q_{j}(\bar{s})+(1-\phi) q_{j}(\underline{s})\right]^{\frac{1}{1-\theta}}} \cdot \frac{1}{\eta_{t-1}^{C A P}}
$$

Equivalently, $\frac{1}{1-\tau_{t-1}}=Q_{1}^{C A P}+Q_{2}^{C A P} \frac{1}{\eta_{t-1}^{C A P}}$, where the coefficients depend on parameters, $Q_{1}^{C A P}=\pi_{l}+\phi \pi_{h} \in(0,1)$ and $Q_{2}^{C A P}=\phi \pi_{h}(1-\phi)\left[q_{h}(\bar{s})-q_{h}(\underline{s})\right] \cdot \frac{\left[\phi q_{h}(\bar{s})+(1-\phi) q_{h}(\underline{s})\right]^{\frac{\theta}{1-\theta}}}{\sum_{j} \pi_{j}\left[\phi q_{j}(\bar{s})+(1-\phi) q_{j}(\underline{s})\right]^{\frac{1}{1-\theta}}}$. Since $Q_{1}^{C A P}>0$ and $Q_{2}^{C A P}>0$, it is easy to see that $\frac{\partial \eta_{t-1}^{C A P}}{\partial \tau_{t-1}}<0$. In particular, if taxes are eliminated, i.e., $\tau_{t-1}=0$, the minimum regulatory capital is higher, i.e., $\eta_{t-1}^{C A P}=\frac{Q_{2}^{C A P}}{1-Q_{1}^{C A P}}$.

Next, we show that interest rate policy $\frac{1}{p_{t-1}}=\frac{1}{\beta}$, binding leverage regulation, i.e., $z_{t-1}=\eta_{t-1}^{L E V} d_{t-1}$, and a profit tax, i.e., $\tau_{t-1} \geq 0$, implement the social optimum as a compet- 
itive equilibrium with bankruptcy. Moreover, we show there is a trade-off between leverage regulation and taxes, i.e., $\frac{\partial \eta_{t-1}^{L E V}}{\partial \tau_{t-1}}<0$. If tax rates are low, the maximum regulatory leverage, $1 / \eta_{t-1}^{L E V}$, necessary to implement the social optimum is low.

If leverage regulation binds, equation $(A .5)$ implies that $\frac{1}{p_{t-1}}=\frac{1}{\tilde{p}_{t-1}}$. Moreover, the proof of Proposition 2 shows that in order to implement the social optimum as a competitive equilibrium, we must have $R_{t-1}^{d}=\frac{1}{\tilde{p}_{t-1}}=\frac{1}{\beta}$. Thus, with binding leverage regulation in place, the interest rate policy satisfies $\frac{1}{p_{t-1}}=\frac{1}{\beta}$.

Equation $(A .12)$ becomes:

$$
\frac{\eta_{t-1}^{L E V} d_{t-1}}{1-\tau_{t-1}}=k_{h, t-1}^{S P}\left[\phi \pi_{h} \frac{q_{h}(\bar{s})}{\phi q_{h}(\bar{s})+(1-\phi) q_{h}(\underline{s})}+\pi_{l}\right]-\left(\phi \pi_{h}+\pi_{l}\right) d_{t-1}
$$

Using $k_{h, t-1}^{S P}=z_{t-1}+d_{t-1}=\eta_{t-1}^{L E V} d_{t-1}+d_{t-1}$ and dividing by $\eta_{t-1}^{L E V} d_{t-1}$ we find

$$
\begin{aligned}
\frac{1}{1-\tau_{t-1}} & =\frac{\eta_{t-1}^{L E V} d_{t-1}+d_{t-1}}{\eta_{t-1}^{L E V} d_{t-1}}\left[\phi \pi_{h} \frac{q_{h}(\bar{s})}{\phi q_{h}(\bar{s})+(1-\phi) q_{h}(\underline{s})}+\pi_{l}\right]-\left(\phi \pi_{h}+\pi_{l}\right) \frac{d_{t-1}}{\eta_{t-1}^{L E V} d_{t-1}} \\
& =\left(1+\frac{1}{\eta_{t-1}^{L E V}}\right)\left[\phi \pi_{h} \frac{q_{h}(\bar{s})}{\phi q_{h}(\bar{s})+(1-\phi) q_{h}(\underline{s})}+\pi_{l}\right]-\left(\phi \pi_{h}+\pi_{l}\right) \frac{1}{\eta_{t-1}^{L E V}} \\
& =\pi_{l}+\phi \pi_{h} \frac{q_{h}(\bar{s})}{\phi q_{h}(\bar{s})+(1-\phi) q_{h}(\underline{s})}+\frac{\phi \pi_{h}(1-\phi)\left[q_{h}(\bar{s})-q_{h}(\underline{s})\right]}{\phi q_{h}(\bar{s})+(1-\phi) q_{h}(\underline{s})} \frac{1}{\eta_{t-1}^{L E V}}
\end{aligned}
$$

Equivalently, $\frac{1}{1-\tau_{t-1}}=Q_{1}^{L E V}+Q_{2}^{L E V} \cdot \frac{1}{\eta_{t-1}^{L E V}}$, where $Q_{1}^{L E V}=\pi_{l}+\phi \pi_{h} \frac{q_{h}(\bar{s})}{\phi q_{h}(\bar{s})+(1-\phi) q_{h}(\underline{s})}>0$ and $Q_{2}^{L E V}=\frac{\phi \pi_{h}(1-\phi)\left[q_{h}(\bar{s})-q_{h}(\underline{s})\right]}{\phi q_{h}(\bar{s})+(1-\phi) q_{h}(\underline{s})}>0$. It is easy to see that $\frac{\partial \eta_{t-1}^{L E V}}{\partial \tau_{t-1}}<0$. In particular, if taxes are eliminated, i.e., $\tau_{t-1}=0$, the maximum regulatory leverage is lower, i.e., $\frac{1}{\eta_{t-1}^{L E V}}=\frac{1-Q_{1}^{L E V}}{Q_{2}^{L E V}}$.

\section{Proof of Proposition 4.}

First, we prove that financial regulations bind in good aggregate states, i.e., at all $t$ such that $s_{t}=\bar{s}$. Given the assumption that high-risk intermediaries are bankrupt at $t+1$ if $s_{t+1}=\underline{s}$, the first order condition with respect to deposits evaluated at the optimal allocation is similar to equation $(A .10)$ in Proposition 3.

$$
\frac{\zeta_{t}^{C A P} \eta_{t}^{C A P}+\zeta_{t}^{L E V} \eta_{t}^{L E V}}{\left(1-\tau_{t}\right) \pi_{h} \lambda_{t+1}^{S P}(\bar{s})}=q_{h}(\bar{s})\left[\theta\left(k_{h, t}^{S P}\right)^{\theta-1}+1-\delta\right]-R_{t}^{d}
$$

where $\lambda_{t+1}^{S P}(\bar{s}) \equiv \lambda^{S P}\left(s^{t+1} \mid s_{t+1}=\bar{s}\right)$.

Moreover, similar to Proposition $3, R_{t}^{d}=\left[\theta\left(k_{h, t}^{S P}\right)^{\theta-1}+1-\delta\right] \cdot \frac{\sum_{s^{t+1} \mid s^{t}} \lambda_{t+1}^{S P} q_{h, t+1}}{\sum_{s^{t+1} \mid s^{t}} \lambda_{t+1}^{S P}}$.

Combining the two equations we find

$$
\begin{aligned}
\frac{\zeta_{t}^{C A P} \eta_{t}^{C A P}+\zeta_{t}^{L E V} \eta_{t}^{L E V}}{\left(1-\tau_{t}\right) \pi_{h} \lambda_{t+1}^{S P}(\bar{s})} & =\left[\theta\left(k_{h, t}^{S P}\right)^{\theta-1}+1-\delta\right]\left[q_{h}(\bar{s})-\frac{\lambda_{t+1}^{S P}(\bar{s}) q_{h}(\bar{s})+\lambda_{t+1}^{S P}(\underline{s}) q_{h}(\underline{s})}{\lambda_{t+1}^{S P}(\bar{s})+\lambda_{t+1}^{S P}(\underline{s})}\right] \\
& =\left[\theta\left(k_{h, t}^{S P}\right)^{\theta-1}+1-\delta\right] \frac{\lambda_{t+1}^{S P}(\underline{s})\left[q_{h}(\bar{s})-q_{h}(\underline{s})\right]}{\lambda_{t+1}^{S P}(\bar{s})+\lambda_{t+1}^{S P}(\underline{s})}>0
\end{aligned}
$$

Thus, to implement the social optimum in good aggregate states, either the capital regulation binds $\left(\zeta_{t-1}^{C A P}>0\right)$ or the leverage regulation binds $\left(\zeta_{t-1}^{L E V}>0\right)$, or both. 
Next, suppose the social optimum in good aggregate states is implemented with binding capital regulation. Similar to equation $(A .11)$ in Proposition 3, we can show that:

$$
\begin{aligned}
\frac{1}{1-\tau_{t}}= & \frac{1}{z_{t}} \frac{\lambda_{t+1}(\bar{s})}{R_{t}^{d} \sum_{s^{t+1} \mid s^{t}} \lambda_{t+1}} \pi_{h}\left\{q_{h}(\bar{s})\left[(\theta+\alpha)\left(k_{h, t}\right)^{\theta}+(1-\delta) k_{h, t}\right]-R_{t}^{d} d_{t}\right\} \\
& +\frac{1}{z_{t}} \frac{1}{R_{t}^{d} \sum_{s^{t+1} \mid s^{t}} \lambda_{t+1}} \sum_{s^{t+1} \mid s^{t}} \lambda_{t+1} \pi_{l}\left[q_{l, t+1}\left[(\theta+\alpha)\left(k_{l, t}\right)^{\theta}+(1-\delta) k_{l, t}\right]+\frac{b_{t}}{\pi_{l}}-R_{t}^{d} d_{t}\right]
\end{aligned}
$$

Next, we transform this equation using $z_{t}=k_{t} \eta_{t}^{C A P}, \frac{d_{t}}{z_{t}}=\frac{k_{h, t}-k_{t} \eta_{t}^{C A P}}{k_{t} \eta_{t}^{C A P}}=\frac{k_{h, t}}{k_{t} \eta_{t}^{C A P}}-1$, the households first order condition $R_{t}^{d} \sum_{s^{t+1} \mid s^{t}} \lambda_{t+1}=\frac{\lambda_{t}}{\beta}$, the fact that $b_{t}=\frac{k_{h, t}-k_{t}}{\tilde{p}_{t}}$, and the expression for $\tilde{p}_{t}=\frac{\sum_{s^{t+1} \mid s^{t}} \lambda_{t+1}}{\left[\theta\left(k_{l, t}^{S P}\right)^{\theta-1}+1-\delta\right] \cdot \sum_{s^{t+1} \mid s^{t}} \lambda_{t+1} q_{l, t+1}}$ (derived from the first order condition with respect to $\left.\tilde{b}_{l, t}\right)$. We obtain:

$$
\begin{aligned}
\frac{1}{1-\tau_{t}}= & \frac{\lambda_{t+1}(\bar{s})+\lambda_{t+1}(\underline{s}) \pi_{l}}{\sum_{s^{t+1} \mid s^{t}} \lambda_{t+1}}-\frac{\lambda_{t+1}(\bar{s})+\lambda_{t+1}(\underline{s}) \pi_{l}}{\sum_{s^{t+1} \mid s^{t}} \lambda_{t+1}} \cdot \frac{k_{h, t}}{k_{t}} \cdot \frac{1}{\eta_{t}^{C A P}} \\
& +\frac{\beta \lambda_{t+1}(\bar{s})}{\lambda_{t}} \cdot \frac{1}{k_{t}} \sum_{j \in\{h, l\}} \pi_{j} q_{j}(\bar{s})\left[(\theta+\alpha)\left(k_{j, t}\right)^{\theta}+(1-\delta) k_{j, t}\right] \cdot \frac{1}{\eta_{t}^{C A P}} \\
& +\frac{\beta \lambda_{t+1}(\underline{s})}{\lambda_{t}} \cdot \frac{1}{k_{t}} \pi_{l} q_{l}(\underline{s})\left[(\theta+\alpha)\left(k_{l, t}\right)^{\theta}+(1-\delta) k_{l, t}\right] \cdot \frac{1}{\eta_{t}^{C A P}} \\
& +\frac{\beta}{\lambda_{t}} \cdot\left[\left[\theta\left(k_{l, t}\right)^{\theta-1}+1-\delta\right] \cdot \sum_{s^{t+1} \mid s^{t}} \lambda_{t+1} q_{l, t+1}\right]\left(\frac{k_{h, t}}{k_{t}}-1\right) \cdot \frac{1}{\eta_{t}^{C A P}}
\end{aligned}
$$

Note that equation $(A .13)$ takes the form $\frac{1}{1-\tau_{t}}=Q_{1, t}^{C A P}+Q_{2, t}^{C A P} \cdot \frac{1}{\eta_{t}^{C A P}}$.

Next, suppose the social optimum in good aggregate states is implemented with binding leverage regulation. Going through similar steps as the ones above, we can show that $\frac{1}{1-\tau_{t}}=$ $Q_{1, t}^{L E V}+Q_{2, t}^{L E V} \cdot \frac{1}{\eta_{t}^{L E V}}$.

\section{Proof of Proposition 5.}

Given the assumption that no intermediary is bankrupt at $t+1$ for any $s_{t+1} \in\{\bar{s}, \underline{s}\}$, the first order condition with respect to deposits evaluated at the optimal allocation is:

$$
\zeta_{t}^{C A P} \eta_{t}^{C A P}+\zeta_{t}^{L E V} \eta_{t}^{L E V}=\left(1-\tau_{t}\right) \sum_{j \in\{h, l\}} \pi_{j} \sum_{s^{t+1} \mid s^{t}} \lambda_{t+1}\left\{q_{j, t+1}\left[\theta\left(k_{j, t}\right)^{\theta-1}+1-\delta\right]-R_{t}^{d}\right\}
$$

If the competitive equilibrium allocation coincides with the social optimum, then the first order conditions in these two environments yield $\sum_{s^{t+1} \mid s^{t}} \lambda_{t+1}\left[q_{j, t+1}\left(\theta\left(k_{j, t}\right)^{\theta-1}+1-\delta\right)-R_{t}^{d}\right]=$ 0 for any $j \in\{h, l\}$. Thus, we find that $\zeta_{t}^{C A P} \eta_{t}^{C A P}+\zeta_{t}^{L E V} \eta_{t}^{L E V}=0$, i.e., financial regulations do not bind in a bad aggregate state. 
Table 1: Calibrated Parameters

\begin{tabular}{ll}
\hline \hline Parameter/Value & Moment $^{1}$ \\
\hline$\beta=\left(\frac{1}{1.04}\right)^{1 / 4}$ & Annual real interest rate of 4 percent \\
$\theta=0.29$ & Average capital income share for U.S. business sector, 1948-2014 \\
$\Phi=\left[\begin{array}{ll}0.950 & 0.050 \\
0.256 & 0.744\end{array}\right]$ & $\begin{array}{l}\text { Average length and number of expansions and contractions of } \\
\text { U.S. business sector, 1947Q1-2015Q2 }\end{array}$ \\
$\pi_{h}=0.15, \pi_{l}=0.85$ & Share of financial assets of brokers and dealers, 1987Q1-2015Q2 \\
\hline \hline
\end{tabular}

${ }^{1}$ Sources of data: U.S. National Income and Product Accounts and U.S. Flow of Funds accounts. For more details, see Cociuba, Shukayev, and Ueberfeldt (2016). 
Table 2: Estimated Parameters

PANel A

\begin{tabular}{|c|c|c|c|}
\hline PARAMETER & VALUE & & \\
\hline Share of nonfinancial firms & $\pi_{m}=0.6632$ & & \\
\hline Fixed factor income share & $\alpha=0.0002$ & & \\
\hline Depreciation rate & $\delta=0.0257$ & & \\
\hline \multicolumn{4}{|l|}{ Productivity parameters } \\
\hline \multirow[t]{2}{*}{ nonfinancial firms } & $q_{m}(\bar{s})=0.98608$ & & \\
\hline & $q_{m}(\underline{s})=0.94955$ & & \\
\hline \multirow[t]{2}{*}{ low-risk financial firms } & $q_{l}(\bar{s})=0.94968$ & & \\
\hline & $q_{l}(\underline{s})=0.94957$ & & \\
\hline \multirow[t]{2}{*}{ high-risk financial firms } & $q_{h}(\bar{s})=1$ & & \\
\hline & $q_{h}(\underline{s})=0.38221$ & & \\
\hline \multicolumn{4}{|l|}{ PANEL B } \\
\hline \multicolumn{2}{|l|}{ Moments TARGeted ${ }^{1}$} & $\begin{array}{l}\text { Data }^{4} \\
\text { (in \%) }\end{array}$ & $\begin{array}{l}\text { Model } \\
\text { (in \%) }\end{array}$ \\
\hline \multicolumn{2}{|c|}{ Average value added share of corporate nonfinancial sector } & 67.6 & 70.8 \\
\hline \multicolumn{2}{|c|}{ Average equity to asset ratio of the financial sector } & 23.0 & 19.0 \\
\hline \multicolumn{2}{|c|}{ Average capital depreciation rate in economy } & 2.5 & 2.5 \\
\hline \multicolumn{2}{|c|}{ Average peak-to-trough decline in output during contractions ${ }^{2}$} & 6.4 & 7.7 \\
\hline \multicolumn{2}{|c|}{ Coefficient of variation of output ${ }^{3}$} & 4.6 & 3.9 \\
\hline \multicolumn{2}{|c|}{ Coefficient of variation of household net worth ${ }^{3}$} & 8.5 & 8.6 \\
\hline \multicolumn{2}{|c|}{ Average deposits over total household financial assets } & 16.4 & 17.5 \\
\hline \multicolumn{2}{|c|}{ Recovery rate in bankruptcy } & 42.0 & 42.0 \\
\hline
\end{tabular}

${ }^{1}$ Sources of data: U.S. National Income and Product Accounts and U.S. Flow of Funds accounts. The recovery rate in bankruptcy is from Acharya, Bharath, and Srinivasan (2003). ${ }^{2}$ Total output is measured as the real value added for the U.S. business sector. We detrend output by the average growth rate over the period 1947Q1-2015Q2. ${ }^{3}$ We calculate statistic after detrending the variable by the average growth rate over the period 1987Q1-2015Q2. ${ }^{4}$ For more details on the data moments, see Cociuba, Shukayev, and Ueberfeldt (2016). 


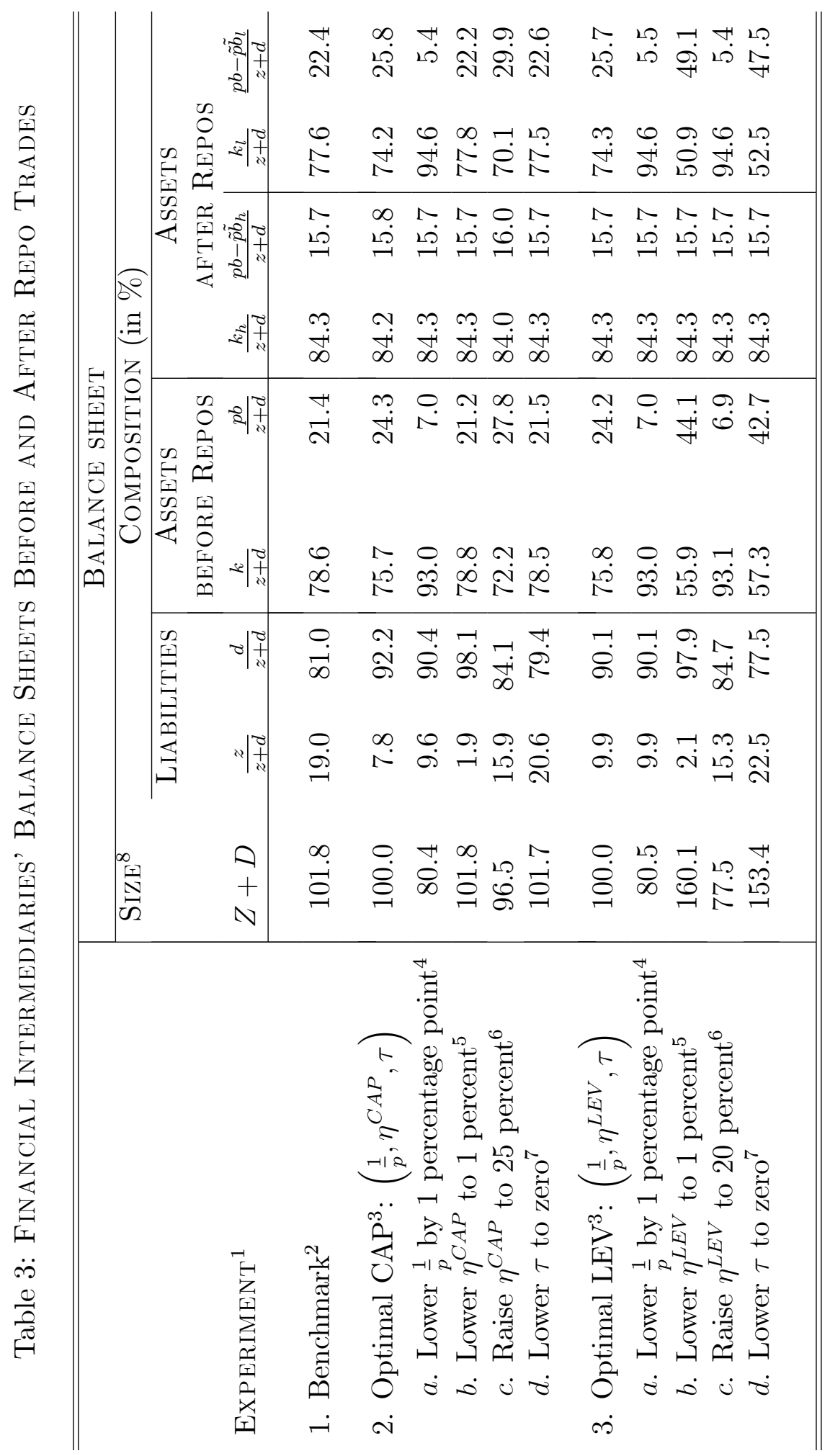

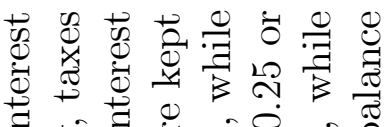

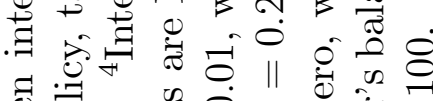

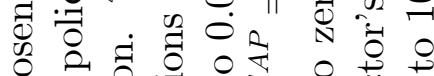
용.

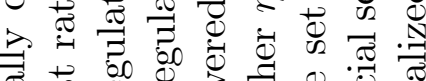

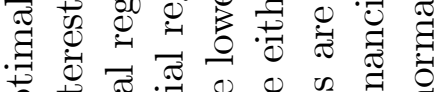

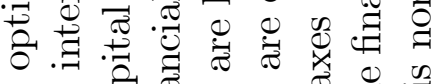

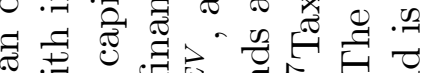

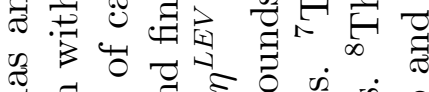

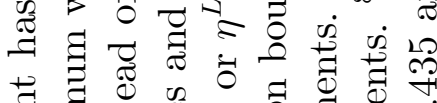

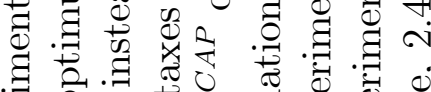

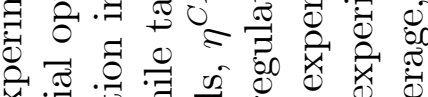

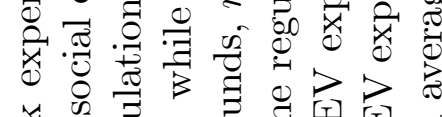
단

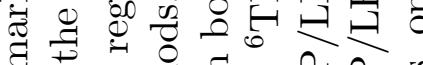

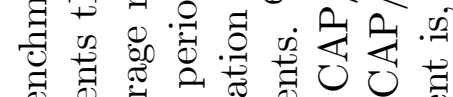
$\checkmark$ 过 인

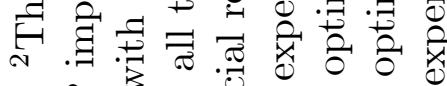

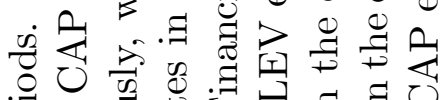

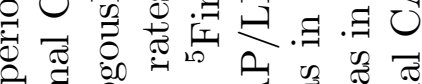

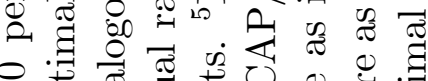

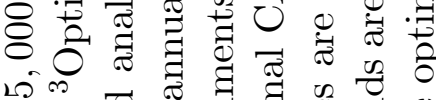

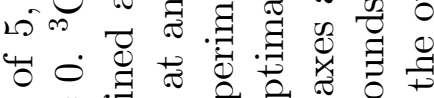

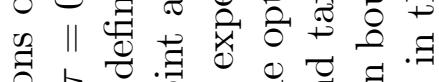

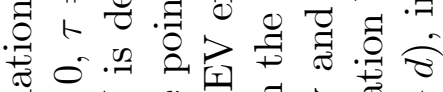

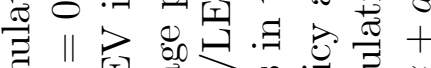

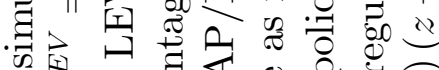
$\dot{0}^{*}=\bar{d}$ ठ

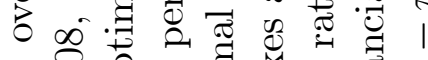

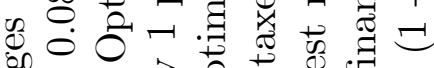
का 11 .

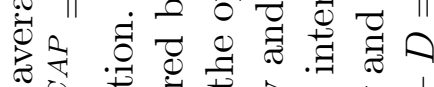
$0=0$

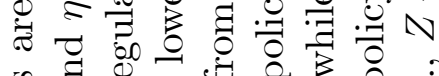
g.

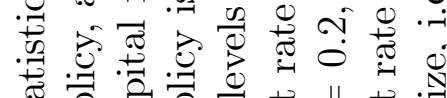

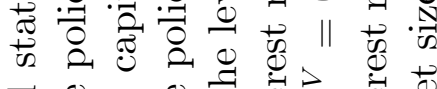

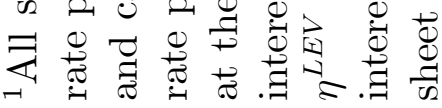


Table 4: Rates of Return, Risk Taking and Welfare

\begin{tabular}{|c|c|c|c|c|}
\hline EXPERIMENT $^{1}$ & \multicolumn{2}{|c|}{$\begin{array}{l}\frac{1}{p} \quad R^{d}-\frac{1}{p} \\
(\text { in } \%)\end{array}$} & $\begin{array}{r}\text { Risk taking }^{2} \\
\text { (in }\end{array}$ & Welfare $^{2}$ \\
\hline 1. Benchmark & 2.21 & 1.78 & 1.73 & -0.0162 \\
\hline 2. Optimal CAP: $\left(\frac{1}{p}, \eta^{C A P}, \tau\right)$ & 2.40 & 1.60 & 0.03 & 0.0000 \\
\hline a. Lower $\frac{1}{p}$ by 1 percentage point & 1.42 & 2.58 & -19.08 & -0.0357 \\
\hline$b$. Lower $\eta^{C A P}$ to 1 percent & 2.21 & 1.79 & 1.78 & -0.0175 \\
\hline c. Raise $\eta^{C A P}$ to 25 percent & 2.65 & 1.34 & -3.37 & -0.0339 \\
\hline$d$. Lower $\tau$ to zero & 2.22 & 1.78 & 1.66 & -0.0147 \\
\hline 3. Optimal LEV: $\left(\frac{1}{p}, \eta^{L E V}, \tau\right)$ & 4.00 & 0.00 & 0.03 & 0.0000 \\
\hline a. Lower $\frac{1}{p}$ by 1 percentage point & 3.01 & 0.99 & -18.97 & -0.0355 \\
\hline$b$. Lower $\eta^{L E V}$ to 1 percent & 3.57 & 0.42 & 59.11 & -0.1970 \\
\hline c. Raise $\eta^{L E V}$ to 20 percent & 4.16 & -0.16 & -22.05 & -0.0429 \\
\hline d. Lower $\tau$ to zero & 3.62 & 0.37 & 52.60 & -0.1609 \\
\hline
\end{tabular}

${ }^{1}$ See footnotes to Table 3 for a description of the experiments. We average rates of return from simulations of 5,000 periods, and then annualize. The return on deposits is 4 percent in all experiments. ${ }^{2}$ The risk taking and welfare measures are averages over 5,000 simulations of 1,000 periods each. 
Figure 1: Timing of Model Events

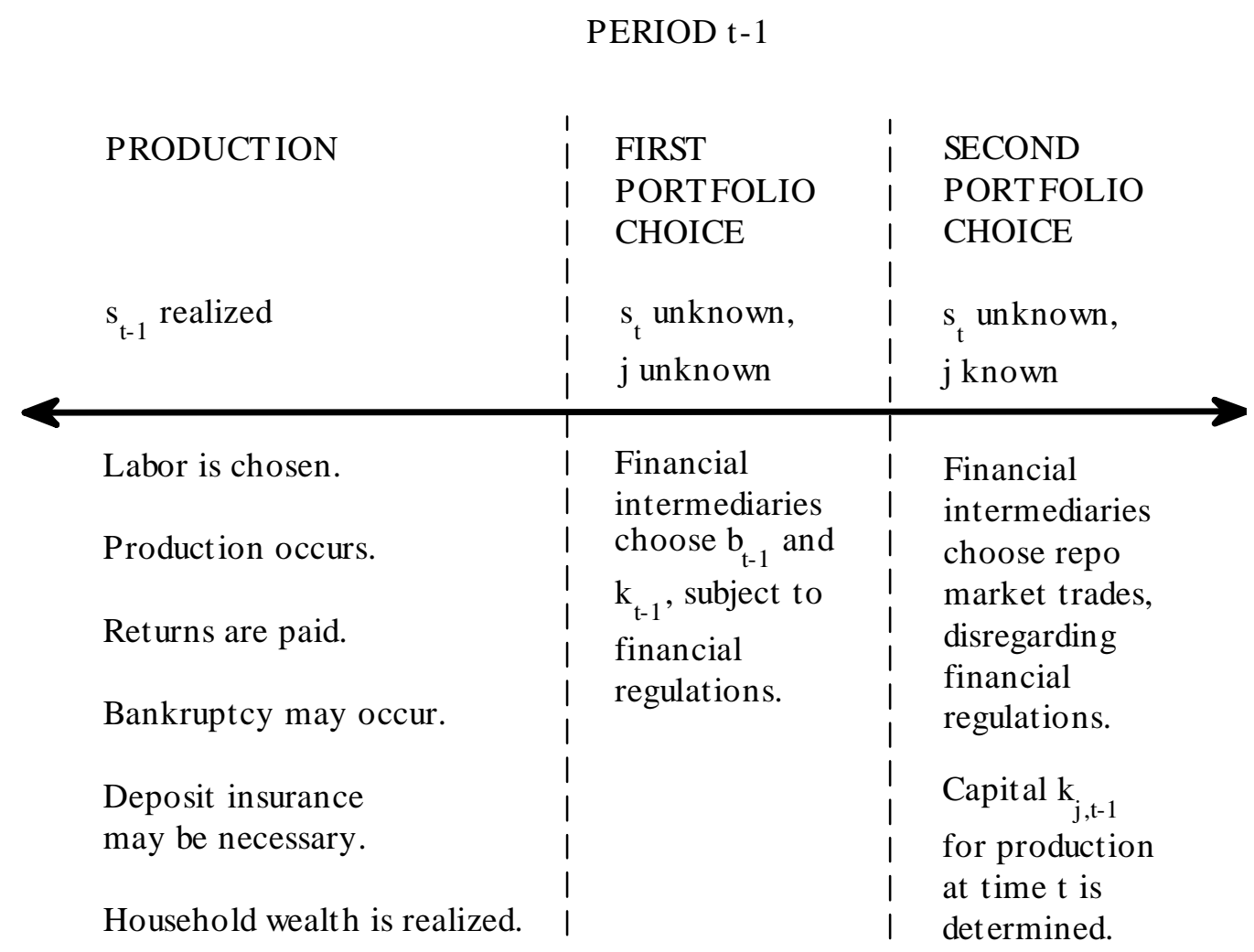


Figure 2: Social Optimum Can be Implemented with $\left(\frac{1}{p}, \eta^{C A P}, \tau\right)$ or $\left(\frac{1}{p}, \eta^{L E V}, \tau\right)$
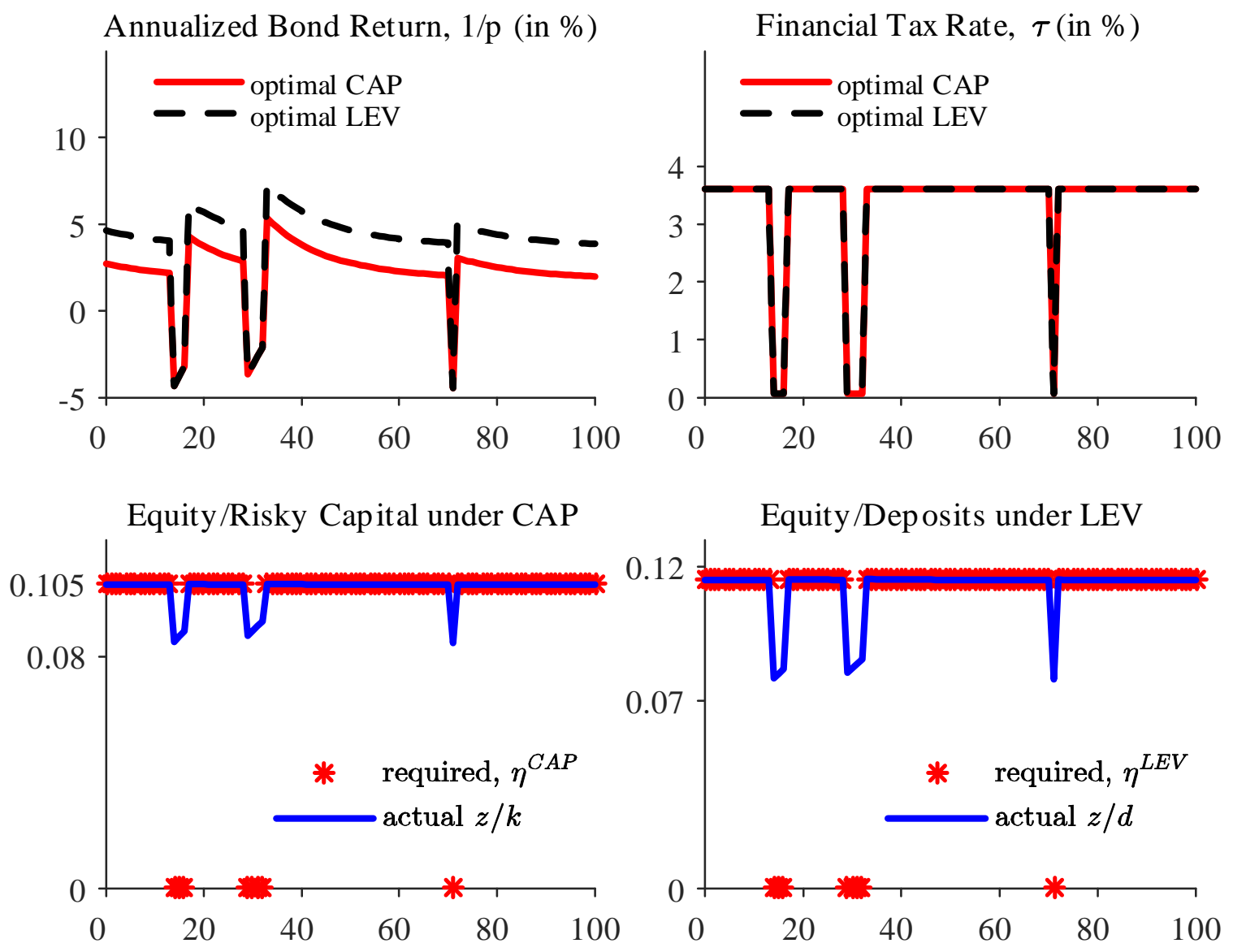
Figure 3: Optimal CAP and Optimal LEV Economies: Balance Sheet Composition and Asset Returns
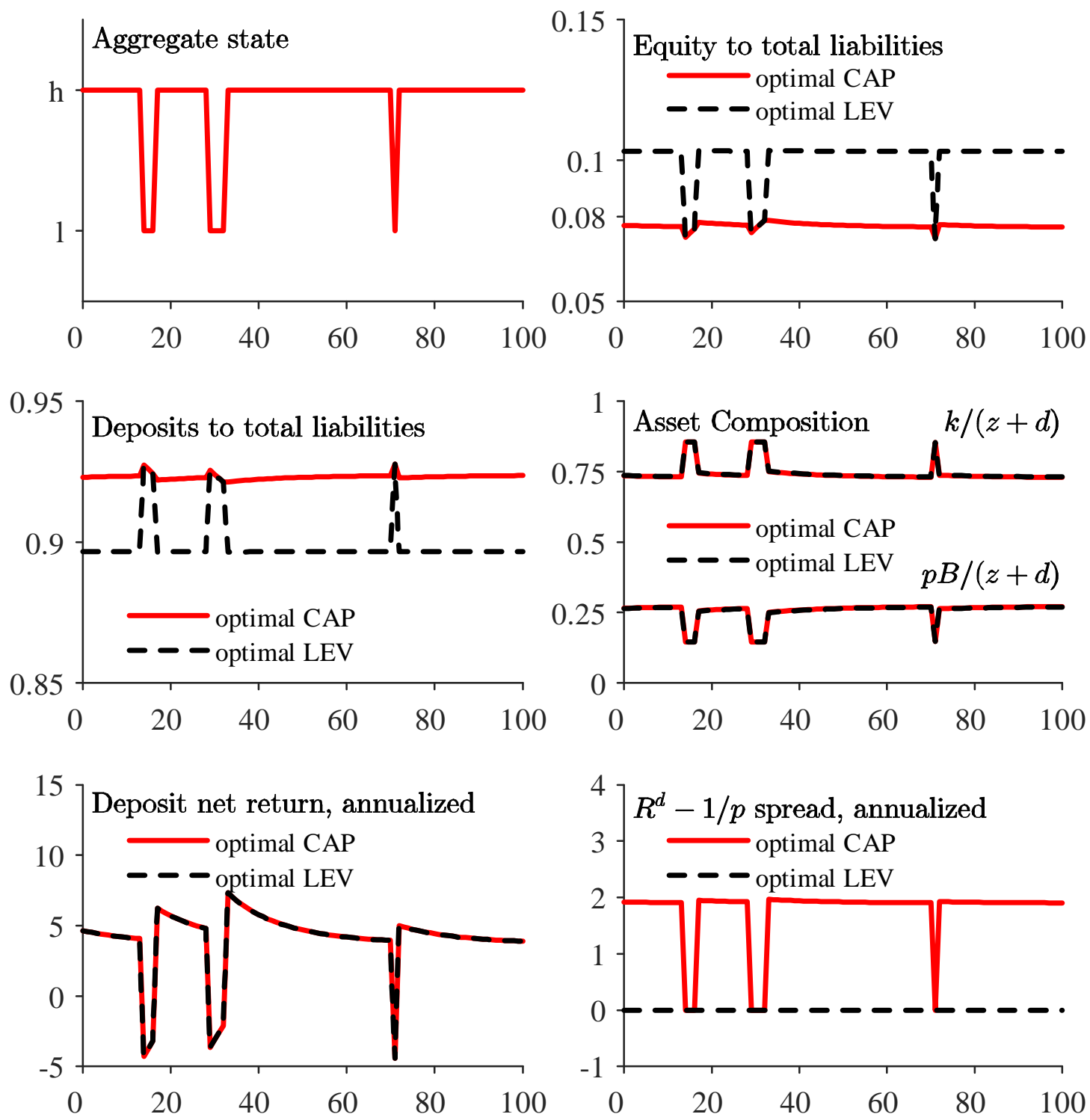
Figure 4: Welfare and Risk Taking Relative to the Social Planner
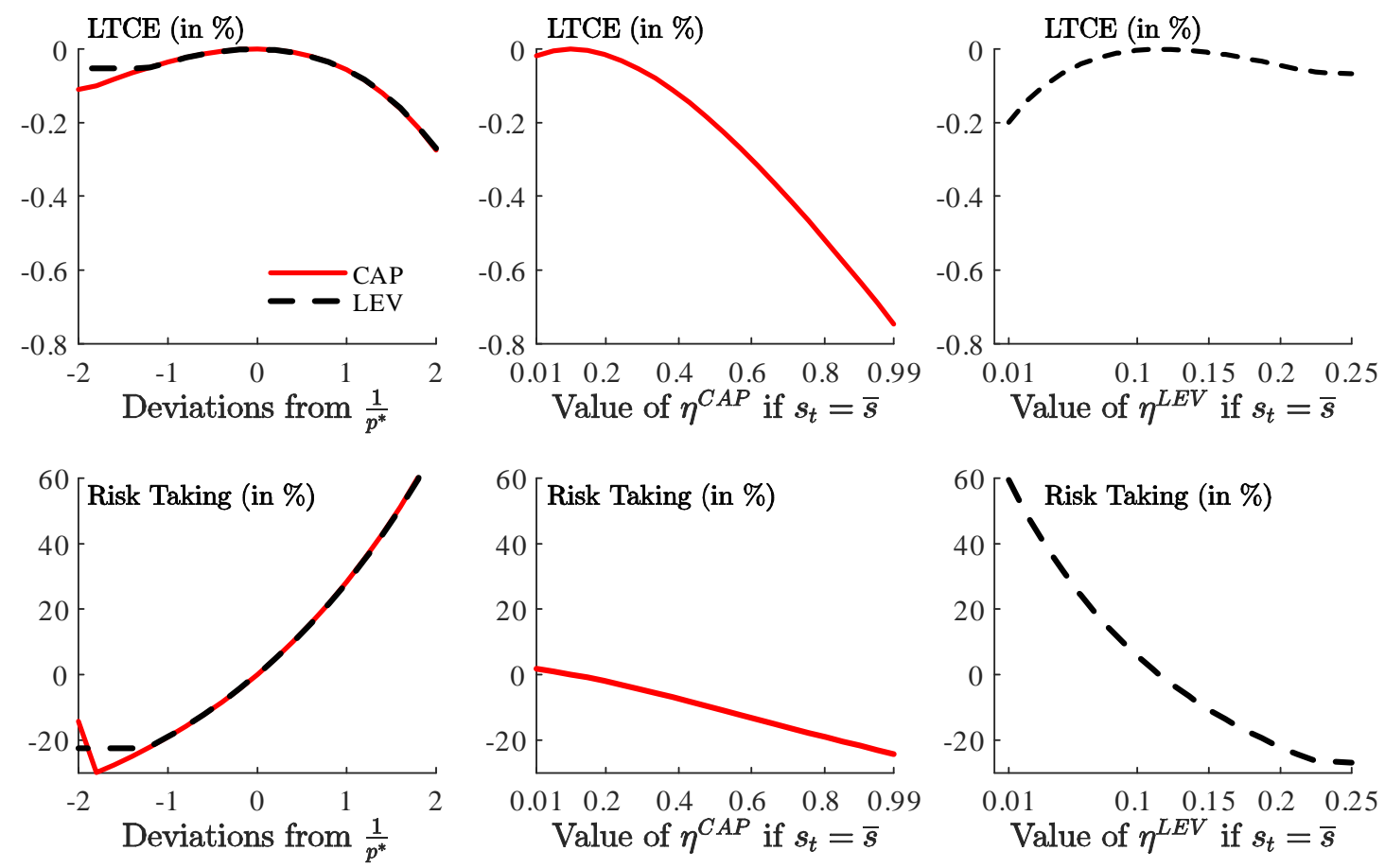